This PDF is a selection from a published volume from the National Bureau of Economic Research

Volume Title: Housing and the Financial Crisis

Volume Author/Editor: Edward L. Glaeser and Todd Sinai, editors

Volume Publisher: University of Chicago Press

Volume ISBN: 978-0-226-03058-6

Volume URL: http://www.nber.org/books/glae11-1

Conference Date: November 17-18, 2011

Publication Date: August 2013

Chapter Title: Mortgage Financing in the Housing Boom and Bust

Chapter Author(s): Benjamin J. Keys, Tomasz Piskorski, Amit Seru, Vikrant Vig

Chapter URL: http://www.nber.org/chapters/c12624

Chapter pages in book: (p. 143 - 204) 


\title{
Mortgage Financing in the Housing Boom and Bust
}

\author{
Benjamin J. Keys, Tomasz Piskorski, Amit Seru, \\ and Vikrant Vig
}

\subsection{Introduction}

The recent domestic financial crisis has become a global phenomenon. With "crisis-like" events unfolding on a regular basis around the world, it is easy to forget that the financial crisis started with the US subprime mortgage market. This is the same part of the market that not so long ago was heralded as a financial innovation that would help propel millions of additional households toward achieving the American Dream. For the first half of the 2000s, it appeared that the American Dream was coming true for more and more households, as the housing market boomed and the home ownership rate hit an all-time high of 69 percent in 2004.

Over the boom period, however, the traditional methods of mortgage finance were undergoing a series of dramatic changes. While mortgages had

Benjamin J. Keys is assistant professor in the Harris School of Public Policy at the University of Chicago. Tomasz Piskorski is the Edward S. Gordon Associate Professor of Real Estate and Finance at Columbia Business School. Amit Seru is associate professor of finance and Neubauer Faculty Fellow at the Booth School of Business, University of Chicago, and a faculty research fellow of the National Bureau of Economic Research. Vikrant Vig is associate professor of finance at London Business School.

This chapter was prepared for the NBER's "Housing and the Financial Crisis" conference on November 17 and 18, 2011. We thank Edward Glaeser, Joseph Gyourko, Chris Mayer, Brian Melzer, Todd Sinai, Shane Sherlund, anonymous external reviewers, and participants at NBER preconference meetings for useful suggestions. We are grateful to Equifax, BlackBox Logic, 1010Data, and Zillow for their data, research support, and infrastructure that were invaluable for the analysis in this chapter. Daniel Hubbard, Laura Vincent, and James Witkin provided excellent research assistance. Piskorski acknowledges the funding from the Paul Milstein Center for Real Estate at Columbia Business School and the National Science Foundation. Seru acknowledges the funding from the Institute of Global Markets at the Booth School of Business at the University of Chicago. For acknowledgments, sources of research support, and disclosure of the authors' material financial relationships, if any, please see http://www.nber .org/chapters/c12624.ack. 
been fixed- or adjustable-rate in the past, nontraditional products, such as hybrid adjustable-rate mortgages (ARMs) and negative amortization contracts, appeared on the scene. Previously rare mortgage products, such as low documentation loans, became commonplace. Borrowers now faced challenging decisions about what type of mortgage was right for them. These new products were financed largely through the expansion of private label securitization, which developed its own set of guidelines, norms, and participants beyond the scope of Fannie Mae and Freddie Mac (the governmentsponsored enterprises, or GSEs). The share of subprime mortgages in total originations increased from 6 percent in 2002 to 20 percent in 2006. As of 2006, the value of US subprime loans was estimated at $\$ 1.5$ trillion, or 15 percent of the $\$ 10$ trillion residential mortgage market. ${ }^{1}$ And yet, just as quickly as these changes occurred, the mortgage market has reverted back to "conservative" underwriting standards, products, and financing in the current post-crisis environment.

In this overview, we trace the rapid evolution of mortgage financing from boom to bust and explore two crucial questions surrounding the market's rise and fall. First, why did the lending boom occur in the size and form that it did? Second, why has the foreclosure crisis been so cataclysmic, but also so heterogeneous across geography and loan types? We organize this chapter around these central questions.

First, in section 4.2, we present a broad set of descriptive statistics and facts regarding the rise and fall of the subprime mortgage market. The subprime market emerged in the late 1990s in a landscape dominated by the GSEs and traditional mortgage terms. We examine why financial innovation occurred in the time and form that it did. Next, we describe how innovation took two separate but complementary paths, through disintermediation and through mortgage contracts. The innovations of private label securitization had a meaningful impact on borrowers, lenders, and investors. These new channels of funding led to a rise in access to nontraditional mortgage products, which had significantly different features than those commonly found in the prime market. We discuss the trends in the availability of these products and the view of the market from its peak in 2006.

We then describe the subsequent housing bust, with an emphasis on the seismic impact that the housing crisis has had on mortgage finance. During the crisis, nontraditional mortgage products performed significantly worse than traditional mortgage contracts. We detail how this led to a collapse of the private label securitization market, and with it the disappearance of nontraditional mortgage products. The GSEs were put into conservatorship by the federal government, but regained their market share back to over 90 percent of the market (in conjunction with the FHA). The thirty- 
year fixed rate mortgage dominated the post-crisis market, and still does today.

In section 4.3, we address the question of why there was a lending boom of this sort. We provide theoretical connections between the optimal financing choices of borrowers and lenders for the emergence of specific products, as well the development of the private label securitization channel for mortgage finance. These theories (e.g., Piskorski and Tchistyi 2010, 2011) also predict a connection between the concentration of these loans and borrowers' characteristics as well as regional house price movements, which are confirmed in the data.

This changed nature of lending had a broad impact on financial intermediation. In particular, we discuss the private securitization process and contrast it with the process used by the GSEs to create mortgage-backed securities. We argue further that, while these nontraditional products were made to inherently riskier borrowers, this is only part of the reason why these mortgages ended up with higher rates of default. We discuss empirical evidence that suggests that their high rates of default reflect not only the greater riskiness of these products and consumers on observable dimensions, but also the ex-ante impact of intermediation on lenders' screening incentives.

The motivation for this section derives from theories of financial intermediation that discuss the role of incentives to help solve moral hazard problems. In particular, balance sheet illiquidity provides a strong economic incentive for lenders to screen and monitor borrowers adequately (Diamond and Rajan 2001). We argue that ease of securitization - driven by the expansion of private label securitization - increased the liquidity of mortgage loans. This liquidity manifests itself on several empirically measurable dimensions such as securitization volume, securitization rates, and the time it takes to securitize a loan. Since securitization increases the liquidity of mortgage loans, a natural question of whether it blunts lenders' incentives to screen arises.

Indeed, the empirical evidence shows that greater loan liquidity did affect lenders' incentives to carefully screen borrowers. We discuss the results of a series of papers by Keys et al. (2009, 2010a, 2010b) and Keys, Seru, and Vig (2012) that provide empirical support for this view. We provide evidence on the heterogeneity of these effects by demonstrating that these effects were present (or easier to detect) among borrowers who took loans with more "soft information." Moreover, by contrasting this result with evidence from the GSE market and the full documentation non-GSE market, we argue that additional mechanisms - either through increased documentation requirements, better monitoring through representations and warranties, or reputational concerns - improved screening incentives of lenders when faced with differential ease of securitization.

More broadly, we discuss several other papers that demonstrate the altered 
structure of financial intermediation (e.g., Mian and Sufi 2009; Rajan, Seru, and Vig 2010; Loutskina and Strahan 2011). In particular, there was a shift in how much mortgage contracts relied on FICO and LTV (loan to value) consistent with investors in the mortgage-backed securities (MBS) making decisions based solely on hard information variables. Moreover, we discuss evidence that identifies agency conflicts in the supply chain of credit. Here we emphasize the composition of originators contributing to the pool. We also discuss several papers that document changes to financial intermediation as well as emphasize similar agency conflicts arising, particularly among privately securitized loans (e.g., Ashcraft and Schuermann 2008; Purnanandam 2011; Jiang, Nelson, and Vytlacil 2010; Nadauld and Sherlund 2009; and Demiroglu and James 2012).

We also ask if the regulatory structure in place was effective in curbing some of these conflicts. Our analysis shows that loans originated in securitization chains that were more heavily regulated performed worse than their less regulated counterparts - suggesting that regulation was largely ineffectual, findings that are consistent with those revealed in several congressional reports in the aftermath of the crisis. ${ }^{2}$ Finally, we conclude this section of the chapter by discussing some of the broad themes that emerge from the empirical work, which have implications for designing private securitization markets going forward.

In section 4.4, we discuss the "prolonged" foreclosure crisis that has prompted a number of policy responses by the government. The crisis, in which house prices fell by 35 percent on average, led to a massive wave of foreclosures. Distressed borrowers who potentially could have renegotiated out of their delinquent (and often underwater) mortgages were rarely able to do so. Why was renegotiation so difficult? We outline two main factors for this difficulty. Both of these factors were aggravated with the general decline of the economy, which led to job losses and repayment problems for many households.

First, we discuss the ways in which aspects of financial intermediation made it more difficult to renegotiate. By its very nature, securitization induces separation of ownership (investors) and control (servicers/banks) of the agents responsible for conducting the renegotiations. The consequent coordination frictions between investors made it difficult to allow banks to conduct renegotiations, even if it may have improved their collective outcomes. We discuss overwhelming evidence in the literature that shows the importance of this factor in limiting renegotiation.

Second, we discuss another challenge to cost-effective mortgage renegotiation: In practice, it may be difficult for the lenders and servicers to easily identify home owners who would default without help. Although millions of

2. The case of the Office of Thrift Supervision's (OTS's) turf war against the FDIC over the regulation of Washington Mutual is a well-known instance (see Agarwal, Lucca, et al. 2012). 
home owners are "underwater" and therefore at risk of default, the majority of these home owners are still making timely mortgage payments and may continue doing so without receiving a mortgage modification. ${ }^{3}$ It could be quite costly to extend benefits to all of these underwater home owners. One possible approach to this problem is to extend benefits only to home owners who are delinquent. ${ }^{4}$ This approach, however, could induce home owners to default in order to obtain modification benefits even though they would not have defaulted otherwise. The extent of such "strategic" behavior crucially depends on the costs of delinquency and on the ability and willingness of households to behave strategically. We identify the extent of such strategic defaulters and argue that their intensity went up over time. We also discuss several factors (such as house prices, leverage) that are correlated with borrowers deciding to default while making payments on their other accounts. In addition, we also discuss recent research by Mayer et al. (2011) that provides empirical evidence that renegotiation programs themselves could also induce additional borrowers toward strategic behavior. Together, these findings suggest potential reasons why it may have been difficult for lenders to identify "eligible" borrowers to renegotiate with in a cost effective manner.

We conclude section 4.4 by discussing the nature of various federal programs that were implemented to curtail the foreclosure crisis. We discuss the objectives behind these programs and discuss recent research by Agarwal, Amromin, et al. (2012) that empirically evaluates the effects of the 2009 Home Affordable Modification Program (HAMP) — one of the largest policy interventions concerning residential mortgage debt that provided intermediaries (servicers) with sizable financial incentives to renegotiate mortgages. Their research suggests that the ability of government to quickly induce changes in the behavior of large intermediaries through financial incentives is quite limited, underscoring significant barriers to the effectiveness of such polices.

We end the chapter by providing a broad perspective on the future of mortgage finance and lessons learned from the last tumultuous decade. Our main takeaway is that the way in which mortgages were financed, above and beyond the characteristics of the individual loan or borrower, had an impact on both the likelihood that the loan was originated and the likelihood that the loan would be renegotiated. However, to be clear, securitization is an important innovation and should be a central part of the mortgage market going forward. The challenge now is to design the securitization chain so as to align incentives between borrowers, lenders, issuers, and investors.

3. See, for example, March 2011 Written Testimony of David H. Stevens, Assistant Secretary of Housing-Federal Housing Administration Commissioner, US Department of Housing and Urban Development.

4. For example, a number of modification programs have made benefits available only to home owners who failed to make at least two monthly mortgage payments (such homeowners are at least "sixty days delinquent"). See Citigroup (2009). 


\subsection{The Housing Boom and Bust}

\subsubsection{Growth in Private Label Securitization and the Changed Nature of Lending}

The modern subprime market developed around the fringes of the prime market, with initial efforts in the mid-1990s to provide loans to borrowers who were credit-constrained, (temporarily) cash-flow constrained, or less creditworthy than the prime "conforming" standards. These loans generally required less money down than prime loans, and thus carried higher interest rates to offset additional risk.

Figure 4.1 shows the volume of subprime originations over time, as compared to the GSEs, Jumbo, and Alt-A loans (the figure includes both purchase and refinance loans). Loans with these types of subprime term structures were relatively new, so little was known about how borrowers

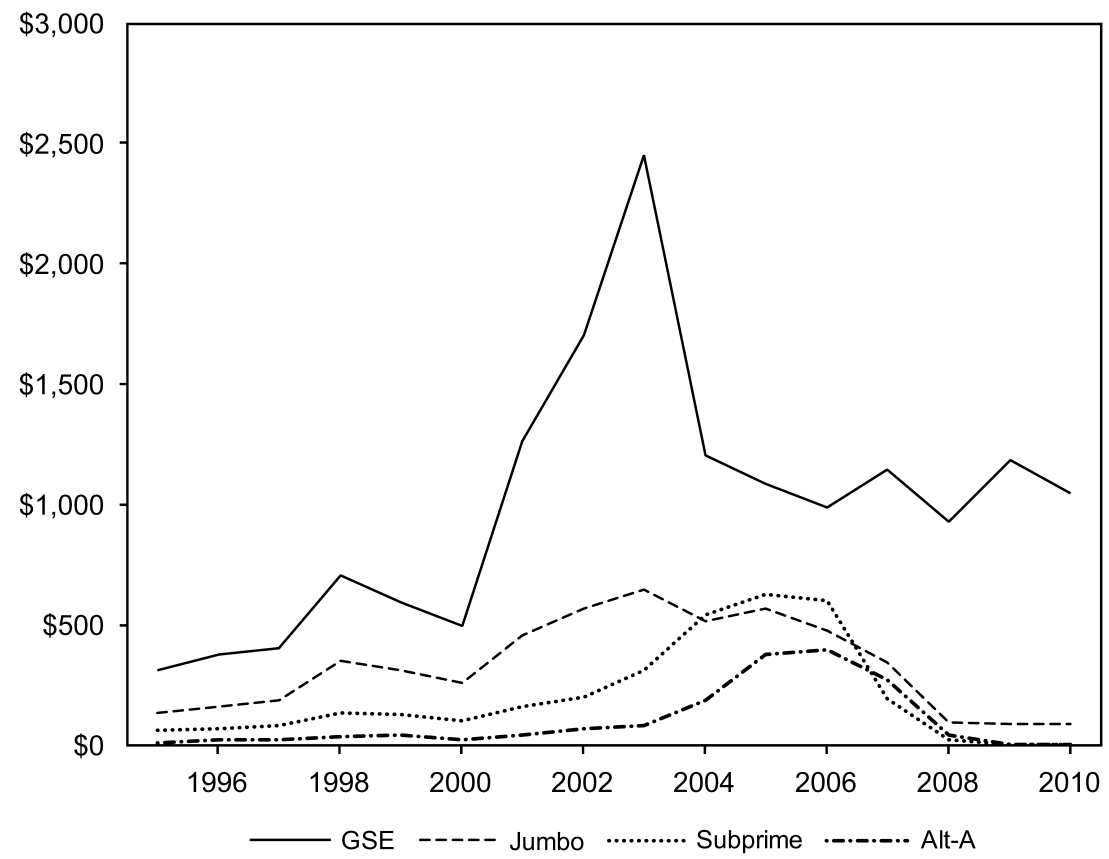

Fig. 4.1 Dollar volume of originations in GSE and private market

Source: www.insidemortgagefinance.com.

Notes: This figure presents the volume of originations (in billions of dollars), both purchase and refinance mortgages, by segment of the mortgage market from 1995 to 2010 . The spike in GSE originations in 2002 and 2003 reflects the refinance boom during that period. Subprime originations increased from near zero in the late 1990s to over $\$ 500$ billion during the peak years of the boom (2004 to 2006). 
would repay. Loans began to default at a faster than anticipated rate in the late 1990s, in conjunction with the dot-com bubble and the turmoil in world markets, and the market briefly scaled back its operations. However, house prices continued to increase and interest rates dropped in the early 2000s, and the subprime market revived rapidly. As house prices rose, potentially distressed borrowers were able to either sell their home or refinance into a new mortgage, obscuring any weaknesses with the structure or sale of these new nontraditional mortgage products (Belsky and Richardson 2010). Not until house prices began to fall did the weaknesses of these products become fully apparent (Demyanyk and Van Hemert 2009). Overall, during 2001 to 2006 the dollar volume of subprime originations ballooned from $\$ 65$ billion in 1995 to over $\$ 500$ billion by 2006 (www.insidemortgagefinance.com). By 2006 , the subprime market was 20 percent of the overall market (by origination volume), up from 6 percent in 2001.

Figure 4.2 shows that not only were there more loans originated but also that more of them were securitized to the private market: subprime/Alt-A

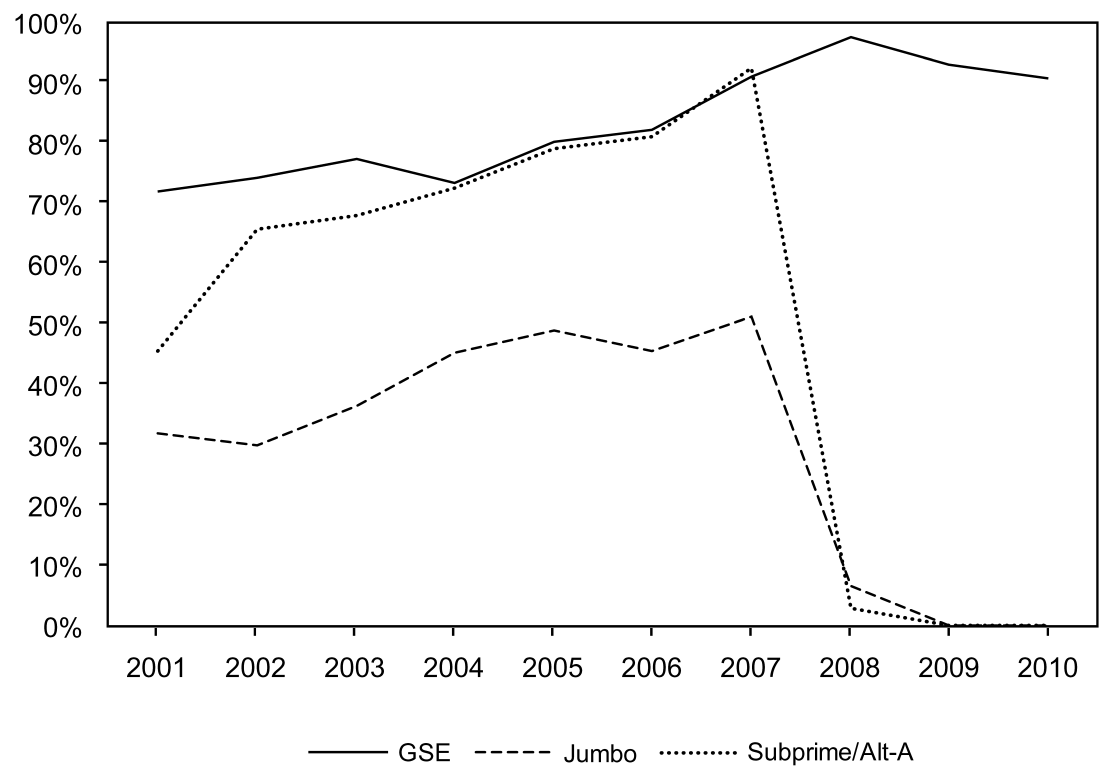

Fig. 4.2 Securitization rates in GSE and private market

Source: www.insidemortgagefinance.com.

Notes: This figure presents securitization rates of conforming loans sold to the GSEs, Jumbo loans, and subprime/Alt-A loans. The GSE loans were more likely to be securitized over the housing boom, but Jumbo and subprime/Alt-A both increased their rates of securitization far more dramatically. Securitization rates of subprime/Alt-A loans rose from less than 50 percent in 2001 to over 80 percent in 2006. The graph shows the collapse of the nonprime market in 2008 , as loans originated outside of the purview of the GSEs are generally no longer securitized. 


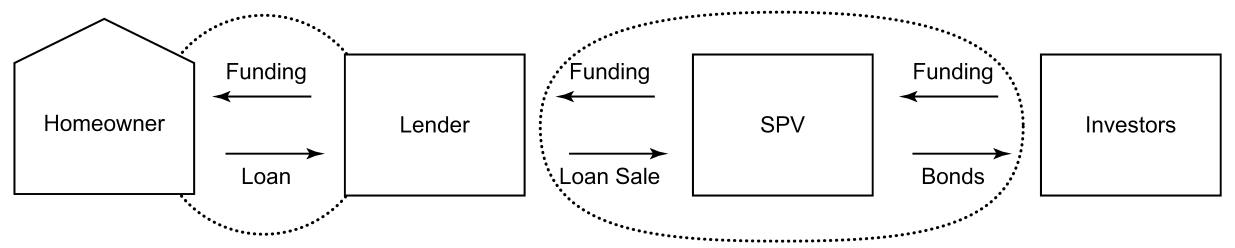

Fig. 4.3 Securitization process in the private market

Notes: This figure provides a simplistic view of the securitization process of subprime residential backed-mortgage securities. After a potential home owner approaches a lender for a mortgage, the lender screens the borrower based on information variables such as credit scores and other indicators of potential financial health of the borrower. Once a loan contract has been accepted, the loans are pooled together in a deal by an issuer. The deal is then tranched and rated before being sold to investors. After sale, the payments and day-to-day management of the deal are handled by the trustee of the SPV. The deals usually have several credit enhancements, which potentially allow the deal to achieve a high rating.

securitization rates went up from less than 50 percent in 2001 to over 80 percent by 2006 (also see Chomsisengphet and Pennington-Cross 2006).

What does private securitization entail? Figure 4.3 provides a stylized description of this process. After a potential borrower approaches a lender for a mortgage, the lender screens the borrower based on information such as credit scores and other indicators of potential financial health of the borrower. Once a loan contract has been accepted, the loans are pooled together in a deal by an issuer. The deal is then tranched and rated before being sold to investors. After sale, the trustee of the SPV (Special Purpose Vehicle) handles the payments and day-to-day management of the deal. The deals usually have several credit enhancements that potentially allow portions of the deal to achieve a high rating. The most popular of these is overcollateralization, where a collateral cushion "over" what was pledged to investors was kept in the deal.

It is worth noting that this process differed from the well-established GSE securitization process. First, the sale in private securitization does not ensure investors from default risk. Second, and more importantly, lenders who sell loans to the GSEs must follow strict guidelines. Their large size allows the GSEs to coordinate and implement standardized practices across various agents in the supply chain of credit. We will reiterate these differences both when we discuss some of our results on the relationship between securitization and screening (section 4.3.2), between securitization and loan renegotiation (section 4.4), and also in our discussion of lessons drawn from the evidence presented in this overview (section 4.5). We now describe the evolution of each of the agents in the supply chain of credit-borrowers, lenders, and investors - over the boom period in turn.

\section{Borrowers}

The best way to show how borrowers financed by the subprime market changed during the boom period is to plot average loan characteristics over 
time. First, we present the time series of average credit scores across three groups of nonprime borrowers. We focus our attention on the category of "subprime" borrowers, defined here based on the B\&C classification of securitized loan pools in the Loan Performance (LP) database. For comparison, we provide information on credit scores on parts of nonprime mortgage segments that followed underwriting standards closer to the GSEs (Alt-A and Jumbo loans). As is evident from figure 4.4, part A, relative to Alt-A and Jumbo loan borrowers, subprime borrowers had significantly lower credit scores (Mayer, Pence, and Sherlund 2009). However, average FICO scores were largely constant in these three subsections of the nonprime market over time. One could also make comparisons with the average credit scores of GSE borrowers over the same time period and reach similar conclusions.

Second, borrowers were able to increase their leverage and decrease their monthly payments by using these new products. As shown in part B of figure 4.4, while the leverage on the first-lien on the homes grew early on, it stabilized around 87 percent. However, there was also a massive increase in the debt taken on second liens (see also Mian and Sufi 2010). The combined LTV (CLTV, which measures the debt from both the first and second liens) increased from 85 percent to 95 percent between 2001 and 2006 (averaged for loans that report CLTV), a finding that is similar to figures reported in Sherlund (2008). This result has been interpreted in the literature as willingness by lenders to provide easier credit - partly due to high house price growth expectations - to borrowers who were willing to buy larger houses and investors who were willing to buy multiple houses.

Third, there was also a dramatic change in the nature of credit on another margin. Lenders were also increasingly willing to reduce the documentation requirements for loans. "Low documentation" mortgages, where less information was collected and verified on potential borrowers' income and assets, had once been extremely rare and usually reserved for high-income, high-wealth entrepreneurs who had difficulty documenting their resources. As investors came to accept FICO and LTV as sufficient statistics for loan default (Rajan, Seru, and Vig 2010), more borrowers provided less documentation. Part $\mathrm{C}$ of figure 4.4 shows the dramatic rise in the proportion of loans with incomplete documentation. Prior to 2000 , fewer than 20 percent of new subprime loans were originated with low or no documentation; by 2006 , this figure approached a full 50 percent of new subprime originations.

\section{Lenders}

Changes to the process of financial intermediation came about concurrently with changes in the composition of mortgage lenders. In contrast to lenders that followed the model of originating the loans as per GSE guidelines and selling to GSEs, lenders in this segment catered primarily to the private market. The largest subprime lenders financed their mortgages through a line of credit, and generally did not intend to retain loans on their books. The subprime lending market was concentrated, with the top 


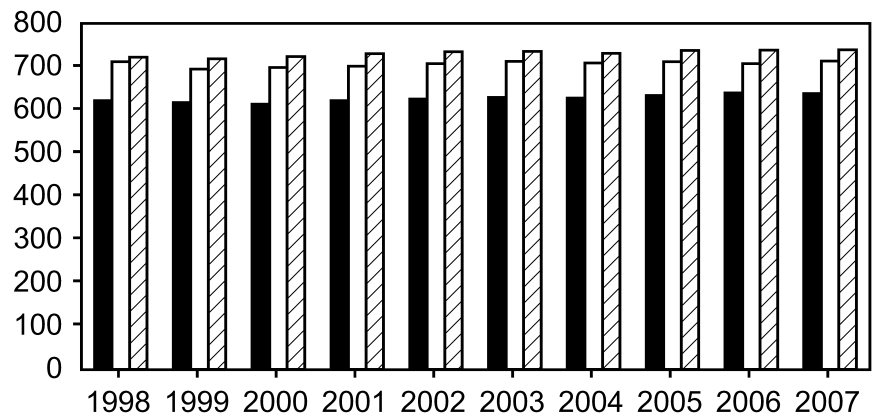

- Subprime $\square$ Alt-A $\square$ Jumbo

B

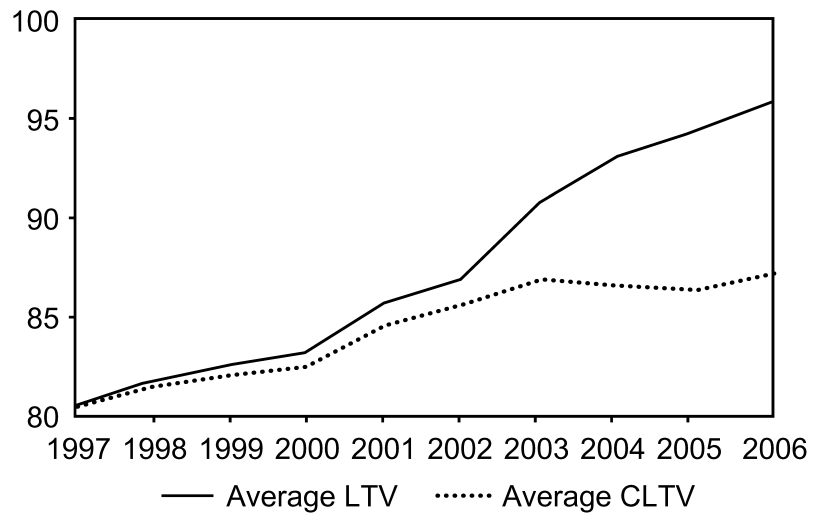

C

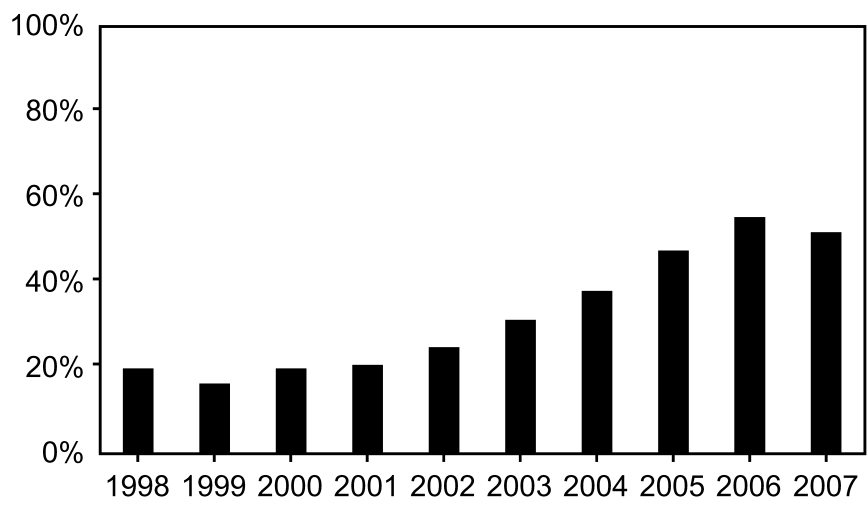

Fig. 4.4 Evolution of FICO, LTVICLTV, and percent low documentation loans in private market

Source: LP database.

Notes: This figure shows the changes to basic borrower and loan quality during the housing boom. Part A shows the average FICO score of borrowers for three types of loans. Although subprime borrowers had lower scores on average than Alt-A or Jumbo borrowers, there was very little change in either the level or difference over the course of the boom. In contrast, part $B$ shows the dramatic increase in CLTV ratios over the boom. While average LTV rose in the late 1990s and early 2000s, CLTV rose sharply beginning in 2003. Part C presents the percent of loans made without complete documentation in the private market. The fraction of low documentation loans peaked at over 50 percent of the private market in 2006. 


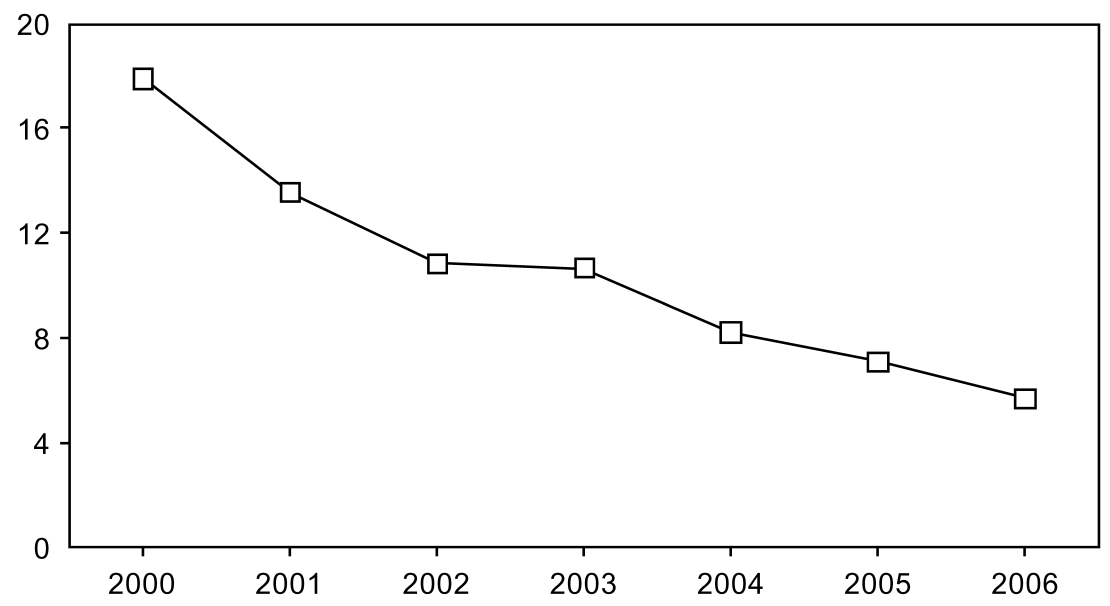

Fig. 4.5 Average time to securitize a loan in private market

Notes: This figure reports the mean time (in months) between origination and securitization for loans sold in the private market. The sample of loans is securitized subprime deals in LoanPerformance database. The figure shows a progressive reduction in how "quickly" a loan could be sold to investors over time starting in 2000. On average, a loan that could be sold only in a year in 2002 was sold within five months during the peak of the subprime boom.

twenty-five lenders originating over 80 percent of all loans (in dollar terms) in the peak years, up from 60 percent in 2001 (www.insidemortgagefinance .com). These lenders tended to be specialists and sold relatively few loans to the GSEs (e.g., New Century, Ameriquest).

The change in the nature of financial intermediation can be observed in two ways. First, banks kept progressively fewer loans on their balance sheets over the housing boom. This can be seen from figure 4.2 regarding the trend in securitization rates over this period. Second, there was also a change in the speed with which these loans could be sold to the private markets. Figure 4.5 shows that on average it took over sixteen months to sell loans in 2000. However, this number saw a 300 percent reduction by 2006 , to only five months' average time to sale. As we will argue in section 5.3.2, these changes had a dramatic effect on the nature of financial intermediation in this market.

\section{Investors}

While it is hard to provide any substantial data on whether there was a change in the nature of investors in mortgage-backed securities, we do provide one piece of evidence that is suggestive. In figure 4.6, we plot the average number of tranches into which cash flows of each pool in a given vintage year were divided. We collect information on the number of tranches across all subprime pools in a given year from Bloomberg. As can be observed from figure 4.6, the average number of tranches increased by roughly 150 percent from 2001 to 2006 - increasing from about eight tranches to about twenty-five 


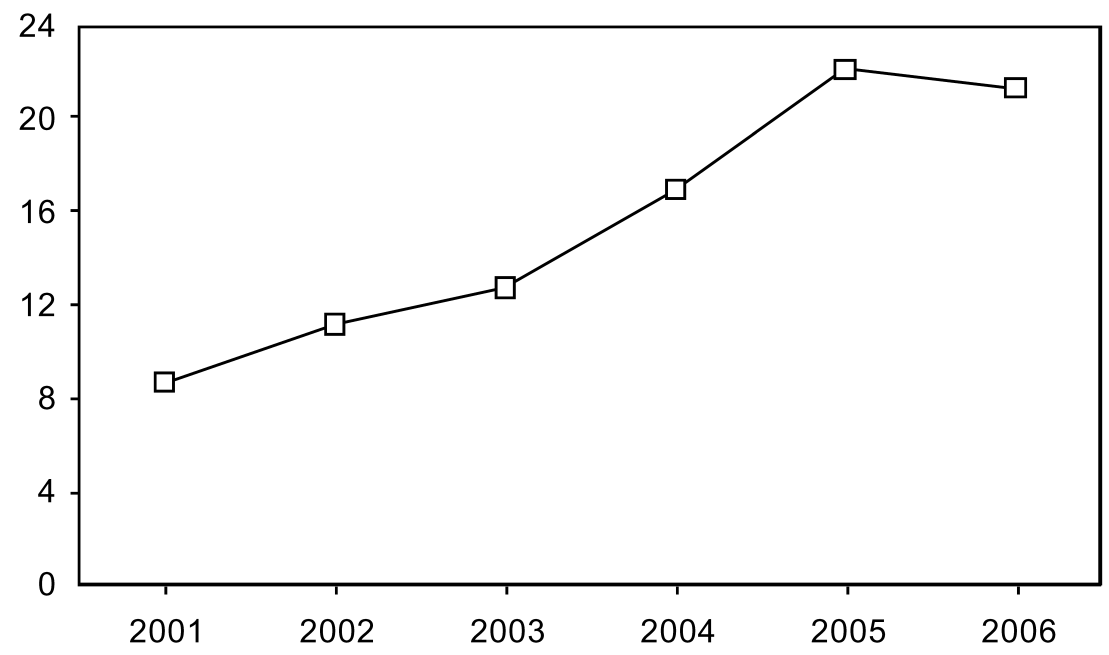

Fig. 4.6 Average number of tranches in an MBS pool in the private market

Notes: This figure reports the mean number of tranches across all the securitized subprime deals in the LoanPerformance database. We also cross-check that these tranches are similar to those reported in Bloomberg. In case of discrepancy, we do drop the deal. We did not get reliable information for 2000. As can be observed, there is a dramatic increase in number of tranches backed by the mortgage collateral progressively from 2001 to 2006.

per pool. This evidence suggests that there was a change in the clienteles that purchased the bonds backed by subprime collateral from 2001 to 2006.

This evidence is also consistent with the popular narrative that there was a change in the nature of credit supply driven by the global savings glut (as described, for instance, by Buiter 2008) as well as several regulated investors (like pension funds and insurance companies). In part, it has been argued that these investors were attracted to an asset that was rated AAA by the ratings agencies but also provided a better return than the low prevailing Treasury rates. We do not know of any research that provides direct and systematic evidence on the changes to the composition of investors in mortgage-backed securities during this period.

\subsubsection{The Growing Importance of Less Traditional Mortgages}

The increase in private label securitization and growth in prominence of less creditworthy, riskier borrowers was accompanied by significant innovations in mortgage design. While the traditional thirty-year fixed-rate mortgage remained a popular instrument, especially among more creditworthy borrowers, other less-traditional instruments gained market share beginning in the early 2000s. While nontraditional mortgages have been used in the past to some degree, during the boom of the 2000s these products were predominately offered to less creditworthy borrowers, allowing them easier access to credit. Most of these new loans were financed though the private 
label securitization channel. As we discuss in section 4.2.3, these nontraditional mortgages performed significantly worse than traditional mortgage contracts during the housing crisis.

Nontraditional mortgages can be classified in two main product categories. The first category of loans are short-term hybrid ARMs such as 2/28 and $3 / 27$ loans, which carry a lower introductory "teaser" rate for the first two (or three) years, after which the rate typically resets to a higher, fully indexed level, for the remaining twenty-eight (or twenty-seven) years of the loan term. The second category consists of loans with a nontraditional amortization structure such as option ARMs or interest only loans. Unlike traditional fixed-rate mortgages (FRMs) or adjustable-rate mortgages (ARMs), option ARMs let borrowers pay only the interest portion of the debt or even less than that, while the loan balance can grow above the amount initially borrowed up to a certain limit, resulting in negative amortization. Under an interest-only loan, the borrower pays only the interest rate on the principal balance, with the principal balance unchanged, for a set term (usually five or ten years). At the end of the interest-only term, the principal balance is amortized for the remaining term. Finally, unlike traditional loans given to prime borrowers, many of these nontraditional mortgages carried costly prepayment penalties.

Short-term hybrid loans were the most popular category among subprime loans. Figure 4.7 shows the concentration of short-term hybrid adjustable

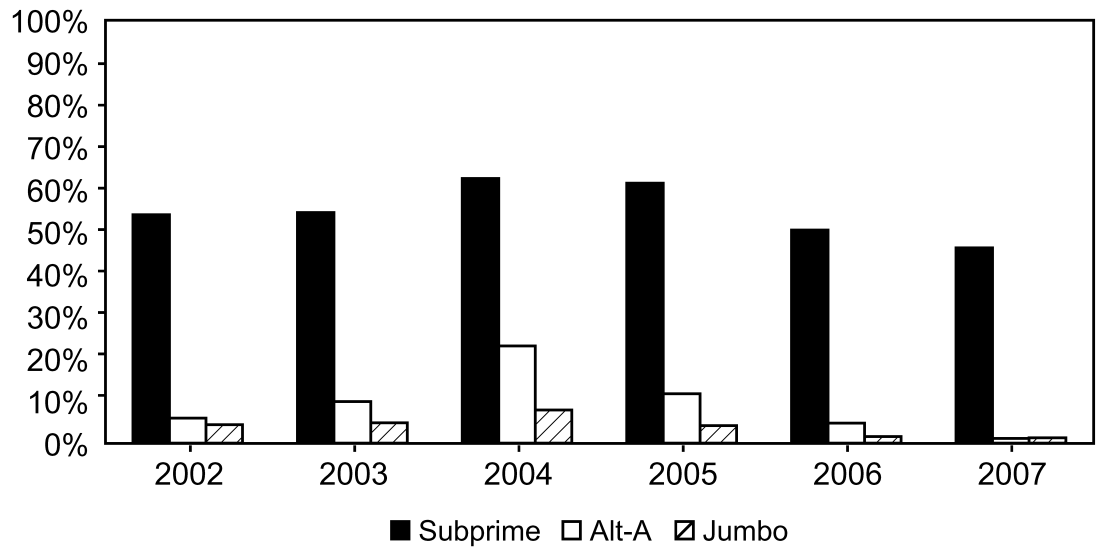

Fig. 4.7 Evolution of short-term hybrid ARMs by credit category in the private market

Source: LP database.

Notes: This figure shows the fraction of loans with short-term hybrid ARMs (2/28 or $3 / 27)$ by credit category in the nonprime market during the housing boom. These types of loans were particularly popular among subprime borrowers. Short-term hybrids made up more than half of all subprime originations during the boom years. This product was rarely used among Jumbo loans, and peaked in 2004 with 20 percent of the Alt-A market, but was generally not used as frequently as in the subprime market. 
rate mortgages with a teaser rate period of up two years among subprime, Alt-A, ${ }^{5}$ and most creditworthy (Jumbo) nonagency securitized loans. As we observe from figure 4.7, short-term hybrid adjustable-rate mortgages were most prevalent among subprime borrowers and overall accounted for more than half of these loans. Including the longer-term hybrid mortgages such as 3/27 ARMs, hybrid loans constitute more than 70 percent of all privately securitized subprime loans. Also we observe that these loans came into significant use among more creditworthy Alt-A borrowers in the 2003 to 2005 period, accounting for as much as 20 percent of all Alt-A loans originated in 2004. Few of these loans were given to most creditworthy Jumbo borrowers. By 2007, these loans became less popular and were limited almost exclusively to subprime borrowers. We also note that as the origination of subprime loans dramatically increased during the housing boom in the 2000s, so did the share of short-term hybrid loans among all loans originated during this period.

Loans with nontraditional amortization structures such as option ARMs or interest-only loans also experienced rapid growth during the housing boom in the 2000s. From 2003 through 2005, the originations of these loans grew from less than 10 percent of residential mortgage originations to about 30 percent. ${ }^{6}$ Option adjustable-rate mortgages experienced particularly dramatic growth. They accounted for as little as 0.5 percent of all mortgages written in 2003, but their share soared to more than 12 percent of all originations in 2006 (LoanPerformance).

Figure 4.8 shows the concentration of loans with negative amortization among subprime, Alt-A, and Jumbo nonagency securitized loans. While the short-term hybrid loans were mostly a subprime product, negativeamortization loans were by far the most common among Alt-A borrowers. Barely any subprime borrowers took out negative-amortization loans, and no more than 10 percent of jumbo borrowers received these mortgages. Negative-amortization loans went from being relatively uncommon products in 2002 to capturing almost 40 percent of the Alt-A market in 2007, mostly due to a dramatic increase in 2004.

Similarly, figure 4.9 shows the concentration of loans with interest-only repayment structures among subprime, Alt-A, and Jumbo nonagency securitized loans. Interest-only loans were generally concentrated among most creditworthy borrowers, though not exclusively. For much of the sample period, more than half of new Jumbo loans followed an interest-only payment schedule, as did around 40 percent of Alt-A loans. By 2007, interestonly mortgages were almost as common among Alt-A borrowers as among more creditworthy borrowers.

5. The Alt-A category consists of loans that, for various reasons, are considered by lenders to be more risky than prime mortgages and less risky than subprime mortgages.

6. See Government Accountability Office (2006). 


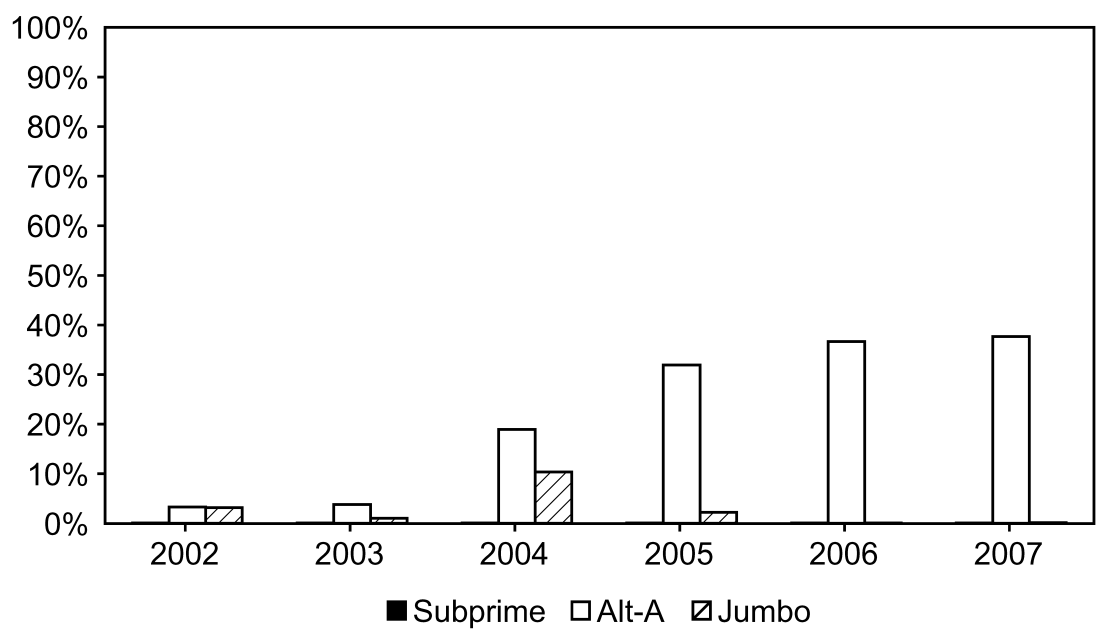

Fig. 4.8 Evolution of negative amortization loans by credit category in the private market

Source: LP database.

Notes: This figure shows the popularity of negative amortization loans in the private market. These loans were largely an Alt-A phenomenon and grew in popularity at the tail end of the housing boom, especially in high house price appreciation markets.

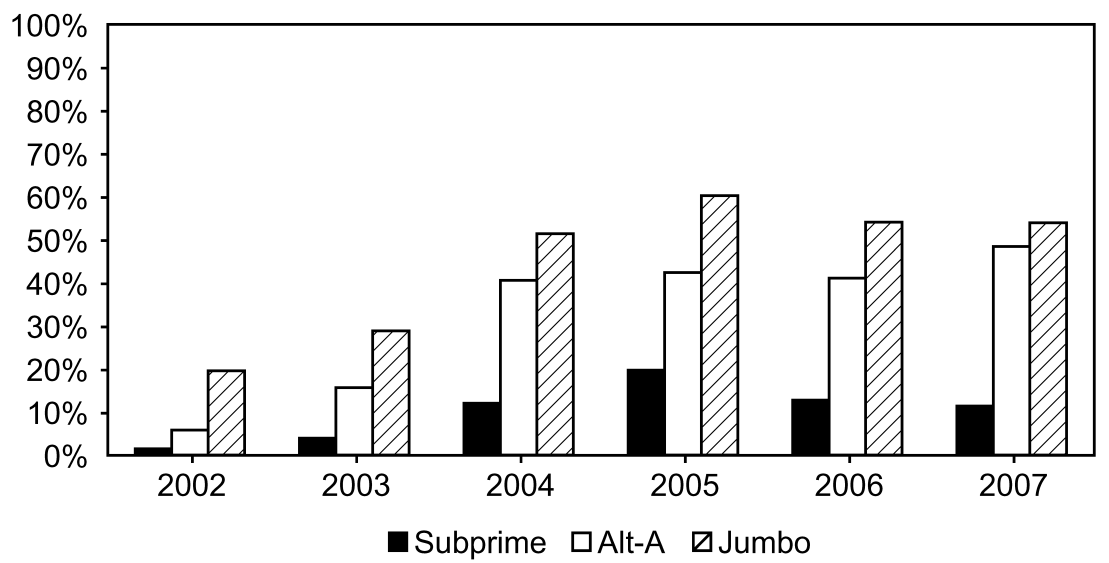

Fig. 4.9 Evolution of interest-only loans by credit category in the private market

Notes: This figure presents the use of interest-only loans in the nonprime mortgage market during the housing boom. Interest-only loans were extremely common in both the Alt-A and Jumbo segments but much less so in the subprime market. In 2005, over 50 percent of all Jumbo loans had an interest-only structure, while 40 percent of Alt-A loans had this structure. 
Finally, we note that this growth in usage of nontraditional mortgages was accompanied by a significant increase in the usage of prepayment penalties. These clauses have been almost exclusively concentrated among less creditworthy borrowers (subprime and Alt-A). For example, among the 2/28 ARM loans originated in the 2003 to 2006 period more than 74 percent of these loans carry prepayment penalties. On the other hand, among Jumbo borrowers (who have stronger credit profiles) these clauses are virtually nonexistent, with less than 3 percent of these loans having such clauses (www .loanperformance.com).

\subsubsection{The Housing Bust and the Fall of Subprime Lending}

House prices peaked in early 2006, and thereafter turned sharply downward. As figure 4.10 shows, by the end of 2008, national average house prices had fallen more than 30 percent from their peak, according to the Case-Shiller index. This precipitous decline exposed borrowers who had bought nontraditional products, put little money down, and anticipated to easily refinance before payments increased. These borrowers were quickly underwater on their mortgages and began to go into serious delinquency and enter the foreclosure process.

Figure 4.10 also shows the cumulative inventory of loans in foreclosure by product type. We observe that the percentage of loans in foreclosure has increased since 2008 for all product types, and the riskiest mortgages have been hit the hardest. For the universe of US residential mortgages, the cumulative foreclosure rate is 4.1 percent, yet nearly 15 percent of subprime loans and 19 percent of option ARMs are now in foreclosure. Conversely, the cumulative foreclosure rate for agency prime loans, traditionally seen as the
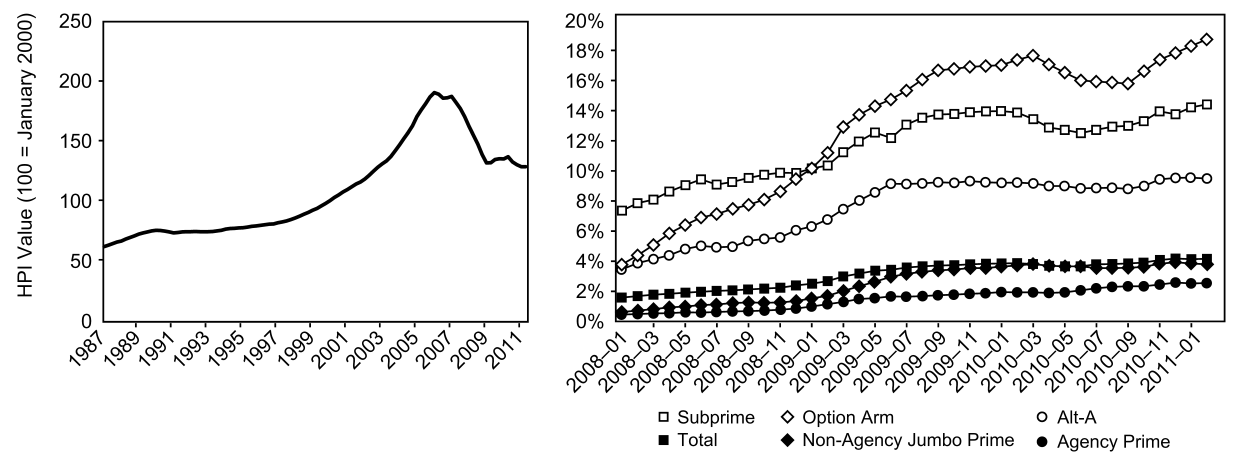

Fig. 4.10 National house price index and total cumulative foreclosure starts by product type

Source: LPS.

Notes: This figure shows the national house price index using S\&P/Case-Shiller data for the period 1987 to 2011 in the left panel. The right panel presents cumulative foreclosure starts by different product category types starting 2008. 


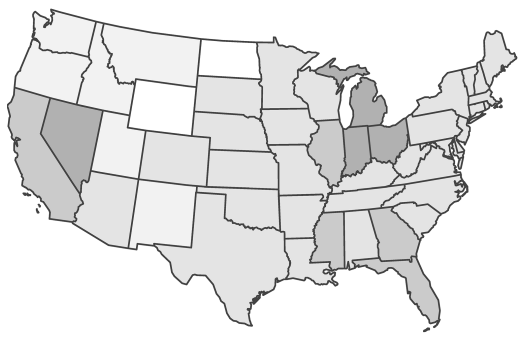

(a) 2007

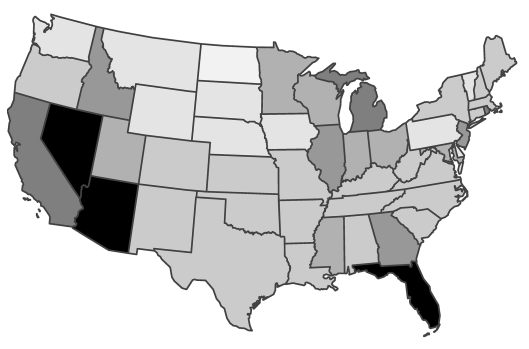

(c) 2009

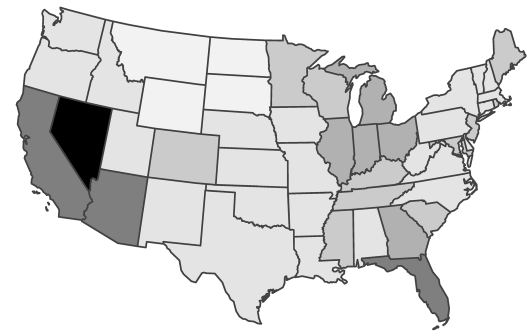

(b) 2008

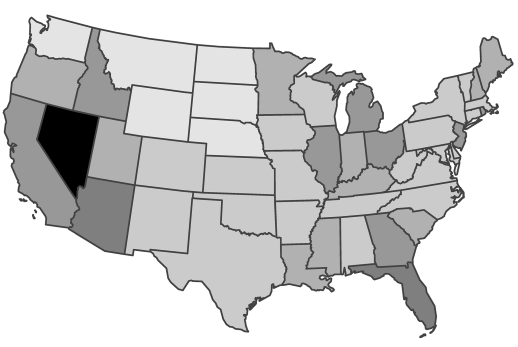

(d) 2010

\section{Fig. 4.11 Foreclosure starts by year and state}

Source: Mortgage Bankers Association data on quarterly foreclosures across states.

Notes: The foreclosure start percentage values range from 0.97 to 13.85 , white being the lowest and black the highest. North Dakota consistently has the lowest rate of foreclosure starts for each year, including the minimum of 0.97 in 2007 . The maximum foreclosure start percentage of 13.85 is seen in Nevada in 2009, which has the highest rate of foreclosure starts in all years except 2007, in which Michigan holds the highest foreclosure start rate of 4.56.

safest group of mortgages, is a relatively modest 3.5 percent (although still substantially elevated relative to its historical average). We see that option ARMs were initially less likely to be in foreclosure than subprime loans, but this trend dramatically reversed over the past three years. This is likely due to the exhaustion of negative amortization limits of option ARMs that temporarily allowed for heavily reduced interest payments.

Figure 4.11 shows foreclosure starts by state for 2007 to 2010 . The percentage values of outstanding loans starting the foreclosure process range from 0.97 to 13.85 , with white being the lowest, and increasing in density to black as the highest. North Dakota consistently has the lowest rate of foreclosure starts for each year, including the minimum of 0.97 in 2007. The maximum foreclosure start percentage of 13.85 is seen in Nevada in 2009, which has the highest rate of foreclosure starts in all years except 2007, when Michigan took the top spot with a foreclosure start rate of 4.56. Figure 4.12 shows the inventory of loans in foreclosure by state in the same period (measured in Q2 of each year). The foreclosure inventory values range from 


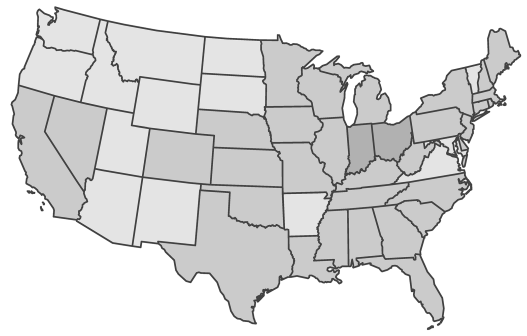

(a) 2007

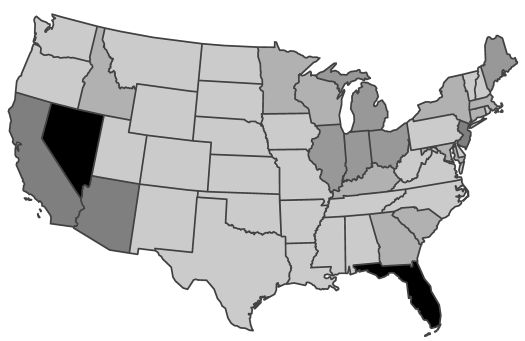

(c) 2009

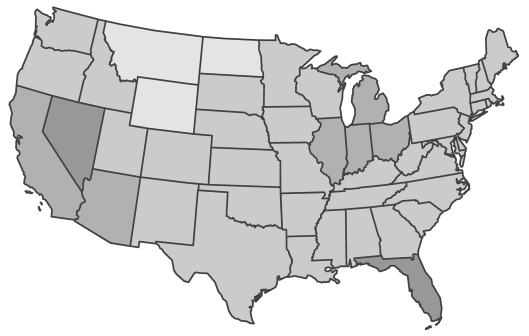

(b) 2008

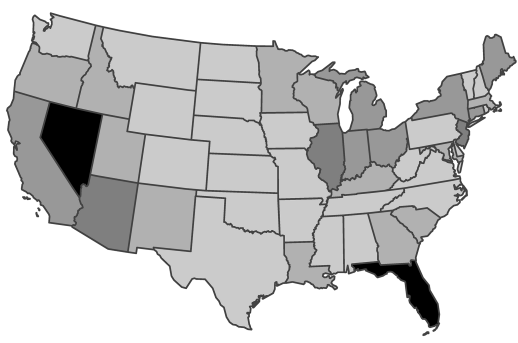

(d) 2010

Fig. 4.12 Foreclosure inventory by year and state

Source: Mortgage Bankers Association data on quarterly foreclosures across states.

Notes: The foreclosure inventory percentage values range from 0.47 to 14.04 , light gray being the lowest and black the highest. The lowest inventory percentage of 0.47 is in Oregon in Q2:2007, with North Dakota consistently having the lowest foreclosure inventory percentage for each Q2:2008, Q2:2009, and Q2:2010. The maximum foreclosure inventory percentage of 14.04 is seen in Florida in Q2:2010. Florida also has the highest foreclosure inventory percentage in Q2:2008 and Q2:2009, while Ohio holds the Q2:2007 maximum for foreclosure inventory percentage at 3.6 .

0.47 to 14.04 percent, with white being the lowest, and increasing in density to black as the highest. The lowest foreclosure inventory percentage of 0.47 is in Oregon in 2007, with North Dakota consistently having the lowest foreclosure inventory percentage for each of the other years. The maximum foreclosure inventory percentage of 14.04 is seen in Florida in 2010. Florida also has the highest percentage in 2008 and 2009, while Ohio holds the 2007 maximum at 3.6 percent.

It is clear from figure 4.12 that the inventory of homes in foreclosure increased during the period between 2007 and 2010. In 2007, the inventory was largely concentrated in the Midwest, particularly in Indiana and Ohio, states that had been hit hard by unemployment due to the decline of the manufacturing sector. However, as time passed, the foreclosure inventory in these states remained relatively constant, while the heaviest foreclosure load moved into the states characterized by a dramatic housing bubble, such as Nevada, Florida, California, and Arizona. Generally, the same states that 
show high inventory growth also have high growth in foreclosure starts (figure 4.11), suggesting that inventory growth had more to do with an increase in the number of loans entering foreclosure than a bottleneck in the system preventing foreclosures from being processed and sold. With more recent data, we would potentially be able to see the effects of the "robo-signing" litigation and foreclosure moratoria on growth in foreclosure inventories.

Figures 4.11 and 4.12 also indicate that there is significant geographic dispersion in foreclosure rates. We observe high foreclosure rates in states such as Arizona, California, and Florida. On the other hand, foreclosure rates are low in states such as Colorado and Kansas. This geographical dispersion in foreclosure starts is closely related to the geographical dispersion in the extent of housing boom and bust. States with high house price appreciation and subsequent price collapse have experienced much higher rates of foreclosures compared to the states where changes in house prices were less pronounced. For example, as figure 4.13 indicates, Miami experienced a very significant boom and bust in house prices in 2000s, while Denver saw much more moderate house price changes in the same period. Correspondingly, as we observe from figures 4.11 and 4.12, foreclosures are high in Florida and low in Colorado.

As a wave of delinquencies and foreclosures swept through the states with the largest house price bubbles, MBS and collateralized debt obligations (CDO) markets suffered severe losses. Many of these delinquencies wiped

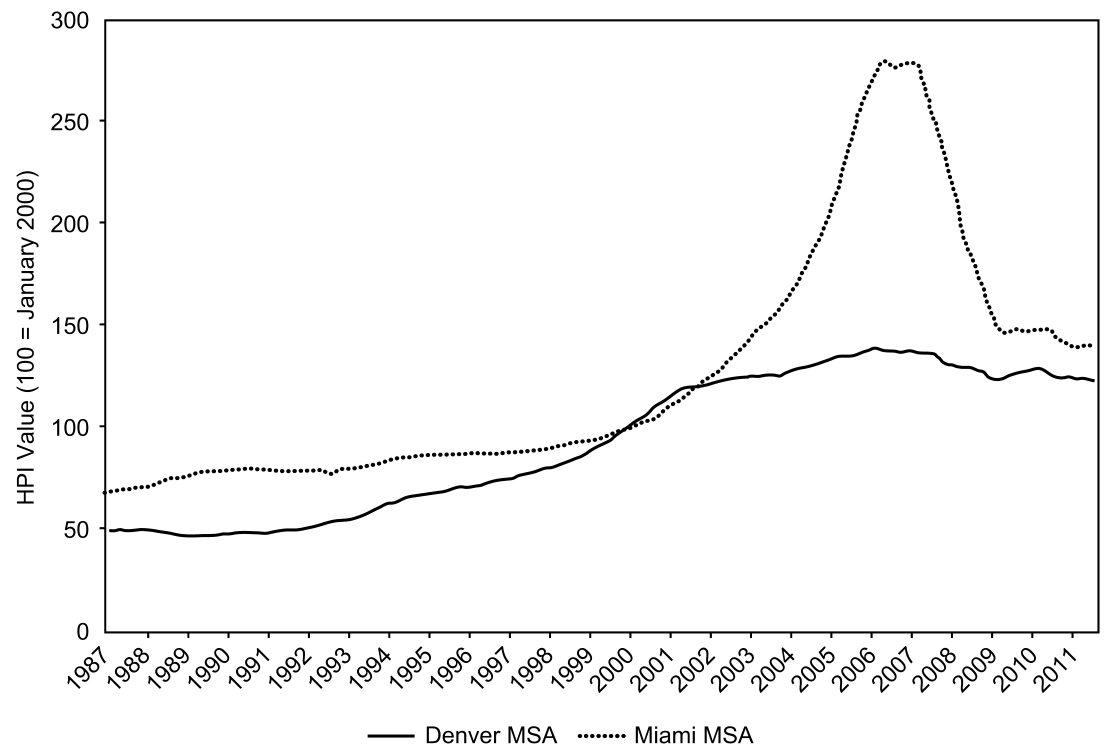

Fig. 4.13 S\&P/Case-Shiller Miami and Denver MSA house price indices Source: S\&P/Case-Shiller data. 
out subordinated tranches and even tranches that were designated triple-A by the rating agencies lost significant value. As investors developed an understanding of the risk of existing loan pools and the difficulty in pricing these pools in the midst of a declining market, the private market for mortgagebacked securities suffered a massive contraction. Whereas over $\$ 1$ trillion was privately securitized in 2005 (subprime + Alt-A + Jumbo), there were essentially no private securitization deals in 2008 (see figures 4.1 and 4.2).

Private label securitization was no longer a viable distribution channel for mortgages, and this financial innovation was effectively discontinued for the time being. Banks either ceased to originate the types of loans that were previously distributed to the nonagency secondary market, or else originated the loan with the intent to hold them on their balance sheets (or to be sold if/when the private market returns).

In September 2008, the federal government took both Fannie Mae and Freddie Mac into conservatorship, effectively nationalizing over $\$ 5$ trillion in MBS and guarantees. The GSEs were allowed to continue to guarantee MBS and also to purchase securities to keep their portfolio roughly constant in size. Fannie and Freddie sharply tightened underwriting standards and broadly instituted "declining market" policies to avoid making loans in markets with falling house prices. The new conforming standard became lower LTV ratios, higher FICO scores, and full documentation and verification of income and assets. Recent congressional efforts have been made to reduce the conforming loan limit as well.

With the private market shut down and Fannie and Freddie constrained by conservatorship, the Federal Housing Administration (FHA) stepped in to fill the financing void. The FHA was largely on the sidelines during the housing boom of the early 2000s, in part due to federal limits on the size of their loans that did not keep pace with the conforming limit. The Economic Stimulus Act of 2008 raised limits on the size of FHA-guaranteed loans, and the agency has continued to offer high LTV loans (97 percent) to highquality, full documentation borrowers. In 2009 and 2010, the FHA backed 24 percent of all originations, which were subsequently securitized through Government National Mortgage Association (GNMA) pools.

By tightening underwriting standards, the second dimension of financial innovation - nontraditional mortgage products - also went into dormancy. Nearly all loans originated after the crisis have been thirty-year fixed-rate mortgages, with only 8 percent of new originations as ARMs in 2009 and 2010 , and essentially no originations of nontraditional products such as interest-only or low documentation loans that proliferated during the boom years.

The crisis may have temporarily halted financial innovation in the mortgage market, or even reversed its course, but these innovations continue to have a direct impact on borrowers. First, borrowers with nontraditional products have been much more likely to go into default and subsequent 
foreclosure. Furthermore, in section 4.4, we describe the role of the securitization chain on the foreclosure process and the frictions introduced when a borrower's delinquent mortgage is owned by a dispersed group of investors. But before we investigate the housing bust, we will explore why subprime products emerged in the first place.

\subsection{Subprime Products' Emergence and Impact}

High default rates among and big losses to lenders and investors in the declining housing market have focused academics' and policymakers' interests on nontraditional mortgage products. One can broadly think of two ways of justifying the emergence of these new products, mostly financed by the private label securitization market. According to the efficiency view, the emergence of these products represented a financial innovation that relaxed households' borrowing constraints in a way that benefited both borrowers and lenders (at least from ex ante perspective, given their possibly overly optimistic expectations regarding the evolution of key variables such as house prices). The alternative view is that these products were designed or misused so that some market participants (e.g., lenders, underwriters) could benefit at the expense of others (e.g., borrowers, MBS investors). We now discuss these views in turn and discuss some empirical evidence that lends support to both of these views.

\subsubsection{An Efficiency View of Mortgage Product Development}

According to the efficiency explanation, either markets had limited efficiency before the development of these products or the underlying economic environment changed sufficiently to justify such development. Consequently, nontraditional mortgages have facilitated an extension of credit to riskier borrowers benefiting both borrowers and lenders (at least from the ex ante perspective).

There are several theoretical papers supporting this view. Piskorski and Tchistyi (2011) provide a formal analysis of optimal mortgage design in a dynamic setting with stochastic growth in house price and income, costly foreclosure, and a risky borrower who requires incentives to repay his debt. They show that in such a setting the features of optimal lending from the perspective of borrowers and lenders are parallel to some key aspects of subprime mortgages. ${ }^{7}$ In particular, during an economic boom when house prices (and borrowers' incomes) are expected to grow it is optimal to extend credit to less creditworthy borrowers, provide them with lower initial payments set to increase over time, and increase borrowers' access to credit as their houses appreciate. This maximizes the benefits of house price appre-

7. See also Makarov and Plantin (2011), who study loans with teaser rates in equilibrium with myopic borrowers. 
ciation for the borrower and lender. ${ }^{8}$ Their model also predicts that a housing slump would result in the tightening of borrowers' access to credit, a foreclosure wave among the least creditworthy, and increased mortgage modification efforts.

In a related analysis, Piskorski and Tchistyi (2010) study optimal mortgage design in a dynamic setting with costly foreclosure, stochastic market interest rate, and a borrower with risky income who requires incentives to repay his debt. They show that the features of the optimal mortgage in such a setting are consistent with an adjustable-rate mortgage with negative amortization (such as an option ARM). The negative amortization provides flexibility for the borrower to cover possible low income realizations, which in turn lowers chances of default inefficiencies. The adjustable interest rate also allows for more efficient management of default risk. Gains from using the optimal contract relative to simpler mortgages are the biggest for those who face more income variability, buy expensive houses given their income level, or make little or no down payment.

The analysis of Piskorski and Tchistyi (2011) implies that mortgages with deferred payments, such as 2/28 and 3/27 ARMs or negative amortization loans, should be more prevalent in locations with higher expected house price and income growth. Also such loans should be concentrated among less creditworthy (subprime or Alt-A) borrowers; that is, those with lower credit scores and lower or more variable incomes (or higher debt-to-income ratios). The analysis of Piskorski and Tchistyi (2010) also implies a high concentration of mortgages with negative amortization among riskier borrowers who at the same time are sufficiently sophisticated to manage such products.

The data appear to be broadly consistent with the key predictions of Piskorski and Tchistyi (2010, 2011). First, figure 4.7 indicates that mortgages with short-term teaser rates are mostly concentrated among risky subprime borrowers. Figure 4.8 indicates that loans with negative amortization features are highly concentrated among riskier borrowers (Alt-A), who at the same time are likely more financially sophisticated than subprime borrowers. ${ }^{9}$

Second, table 4.1 shows the results of regressions when the dependent variable takes the value 1 if a loan is a short-term hybrid ARM (initial rate period between eighteen months and forty-two months), a negative-

8. Early default by the borrower in the boom is costly to the lender, as it does not allow the borrower to use future house appreciation for loan repayment. At the same time, the lender, in order to break even, has to make money on the loan in good times (i.e., periods with prolonged house price growth), as he is likely to lose money in bad times (e.g., during housing crisis). Hence, the interest rate is scheduled to increase over time during the boom. On the other hand, the borrower can afford to pay higher interest rates in the future and is less likely to default in good times, since he can borrow more as the home appreciates in value.

9. See also Cocco (2011), who provides empirical evidence, using the UK household data, that borrowers who took out interest-only mortgages were more likely to have higher future income. 
Short-term hybrid and deferred-amortization regressions

\begin{tabular}{lcc}
\hline & $\begin{array}{c}\text { Pr(short-term hybrid ARM }=1) \\
(1)\end{array}$ & $\begin{array}{c}\operatorname{Pr}(\mathrm{IO} / \mathrm{neg}-\mathrm{am}=1) \\
(2)\end{array}$ \\
\hline LTV & $0.001^{* * *}$ & $-0.003^{* * * *}$ \\
& $(60.14)$ & $(-389.79)$ \\
FICO & $-0.003^{* * *}$ & $0.009^{* * *}$ \\
& $(-2158.73)$ & $(519.05)$ \\
HPI growth & $0.191^{* * *}$ & $0.260^{* * *}$ \\
& $(71.44)$ & $(84.65)$ \\
Dummy (low documentation) & $0.037^{* * *}$ & $0.064^{* * *}$ \\
& $(177.2)$ & $(266.03)$ \\
Other controls & Yes & Yes \\
\hline
\end{tabular}

Notes: This table reports a pair of regressions where the dependent variable in the first regression (1) is an indicator that takes the value 1 if the loan is a short-term hybrid ARM; the dependent variable in the second regression (2) is an indicator that takes the value 1 if the loan is interest-only or negative-amortization. House price growth is a variable that measures the extent of local house price growth during two years prior to mortgage origination. The values in parentheses are the $t$-statistics.

*** Significant at the 1 percent level.

**Significant at the 5 percent level.

*Significant at the 10 percent level.

amortization loan, or an interest-only loan; it takes the value 0 otherwise. Not surprisingly, there is a strong negative coefficient on the origination FICO score. These instruments were mostly concentrated among buyers with lower credit quality. Similarly, low-documentation loans were more likely to be in one of these categories. The relationship with loan-to-value ratio is negative overall, but less clear; this is because Alt-A borrowers (who were more likely to get interest-only or negative-amortization loans) tend not to have high LTV ratios, while subprime borrowers (who were more likely to get short-term hybrid ARMs but not to get deferred-amortization loans) usually do have high LTVs. Lastly, borrowers in "housing bubble" states (California, Nevada, Arizona, and Florida) were significantly more likely to receive these loans than borrowers in the rest of the country. Again, in these very simple regressions, the broad correlations in the data seem consistent with the economic arguments outlined above.

Finally, we note that the very high concentration of prepayment penalties among subprime borrowers compared to their low usage among more creditworthy, prime borrowers has been viewed as one of the key pieces of evidence that lending to risky borrowers was inefficient or predatory. ${ }^{10}$

10. For example, a 2003 report from the Center for Responsible Lending by Goldstein and Son states that: "While some subprime lenders claim that borrowers actually choose prepayment penalties in order to lower the costs of their loan, borrower choice cannot explain the $80 \%$ penetration rate of prepayment penalties in subprime loans in comparison to the $2 \%$ penetration rate in the competitive, more transparent, conventional market. The wide disparity 
However, Mayer, Piskorski, and Tchistyi (2010) show that when considering improvements in a borrower's creditworthiness (such as positive wealth shocks) as one of the reasons for refinancing mortgages, prepayment penalties serve an important role by helping to ensure that mortgage pools are not becoming disproportionately composed of the riskiest borrowers over time. Enforcement of longer-term lending contracts through prepayment penalties allows lenders to charge lower mortgage rates, which reduce the risk of costly default, and to extend credit to the least creditworthy borrowers. This increases welfare, with the riskiest borrowers benefiting the most. ${ }^{11}$ Consequently, a high concentration of prepayment penalties among the riskiest borrowers can be an outcome of an efficient equilibrium in a mortgage market. Mayer, Piskorski, and Tchistyi (2011) also provide empirical evidence consistent with this view.

To summarize, recent theoretical research suggests that nontraditional mortgage products and their high concentration among riskier borrowers may represent a financial innovation benefiting both borrowers and lenders (at least from an ex ante perspective). This research also implies that we should observe high default rates on these new products during the housing crisis. ${ }^{12}$

It is important to note, however, a few key limitations of the aforementioned efficiency results. First, the borrower and lender need to be able to form correct expectations regarding the evolution of key variables (including house prices and income). However, we note that even if this condition is not satisfied, we could think of the aforementioned results as explaining the structure of mortgage contracts given the beliefs of borrowers and lenders. Second, the features of mortgage lending that are optimal at the individual level may have negative consequences at the aggregate level, since the borrower and the lender do not take into account the potential negative externalities that their contract might impose on others. In that sense, mortgage contracts that are ex ante beneficial for borrowers and lenders may overall decrease welfare (due, for example, to the negative externalities of foreclosures). Finally, in deriving optimal contracts, the aforementioned studies assume that the borrower does not face a self-control problem. Borrowers

between the prime and subprime market penetration rates shows that subprime consumers do not "choose" prepayment penalties in any meaningful sense. Rational subprime borrowers with market power should prefer them no more often, and probably less often, than conventional borrowers so that they can refinance into a conventional loan at a significantly lower rate as soon as credit improves" (6).

11. This result is related to Dunn and Spatt (1985), who study the role of due-on-sale clauses and prepayment penalties in a two-period setting in which the borrowers receive ex post stochastic shocks to the incremental utility received from selling the house (from mobility). They show that such clauses may enhance welfare by improving risk-sharing opportunities of borrowers.

12. See Corbae and Quintin (2011) and Campbell and Cocco (2011) for quantitative analysis of defaults on mortgages with deferred payment schedules. 
lacking self-control might abuse access to credit (such as a negative amortization feature), leading to inefficiently high default rates. ${ }^{13}$

If we assume that mortgage product innovation was beneficial to borrowers and lenders (at least from the ex ante perspective), a natural question arises as to why this development had not occurred earlier. There are number of potential explanations. First, since the mid-1990s, mortgage lenders significantly increased their ability to gather and process information. Information technology reduced the costs incurred in the mortgage origination process, and assisted lenders in learning about the credit quality of borrowers and the value of collateral.

Second, during the 2000s, long-term interest rates sustained significant declines that coincided with a vast inflow of capital from abroad into US bond markets (e.g., from China). This led to a significant decline of lenders' cost of capital. Finally, the development of the private label securitization market may have provided better risk-sharing opportunities to investors, thus further reducing the cost of capital. Lower mortgage origination costs coupled with lower cost of capital could have resulted in the extension of credit to less creditworthy borrowers. As nontraditional mortgages can benefit exactly these borrowers, this extension of credit could have triggered widespread development and usage of these products by riskier borrowers.

All these developments occurred in conjunction with each other, and hence through general equilibrium effects that could affect and feed on each other. We note that coinciding with these developments in the mortgage market had been a marked increase in the demand for housing, including second homes, which contributed to fast growth in house prices. ${ }^{14}$ This exuberant environment, in conjunction with anticipated house price appreciation, could provide an additional rationale for the usage of nontraditional mortgages.

\section{Alternative Views on Mortgage Product Development}

An alternative view on mortgage product development postulates that these products were designed or misused so that some market participants (e.g., lenders, underwriters) could benefit at the expense of others (e.g., borrowers, MBS investors). For example, mortgages with teaser rates or negative amortization can allow lenders and mortgage underwriters to defer realization of losses. Hence, these products could facilitate manipulation of the market perception of the risks of these products. In other words, such mortgage contracts may have made the securitization of riskier collateral

13. See Barlevy and Fisher (2010), who present a model and empirical evidence that suggests that speculating borrowers in areas that saw more house price growth increased their demand for deferred amortization loans.

14. See, among others, Khan (2008) and Favilukis, Ludvigson, and Van Nieuwerburgh (2010) for recent general equilibrium studies of house price determination. 
easier or more profitable to lenders and underwriters at the expense of less sophisticated MBS investors. For example, the recent research by Ben-David (2011) suggests that risky subprime lending was associated with artificially inflated transaction prices that allowed sellers of these loans to overstate their quality and earn higher fees. Inflated transactions were common in low-income neighborhoods and were associated with high default rates in the crisis. Moreover, mortgages with a deferred payment schedule, whose returns can be more sensitive to real estate prices than standard contracts, could allow managers of highly levered financial institutions to take on excessive risk (asset substitution). ${ }^{15}$

Alternatively, these nontraditional mortgage products could have allowed lenders to profit at the expense of less sophisticated borrowers. For example, borrowers may not have been fully aware of mortgage resets or existence of the prepayment penalty at the time of signing a contract. Recent research by Bucks and Pence (2008) shows that many borrowers are uninformed about the terms of their mortgage, and this is particularly true for those who have an ARM structure. A more complex nature of these products could have facilitated obfuscation of the true payment structure of these loans. Although direct evidence on lenders extracting rents from mortgage borrowers is difficult to obtain and quantify, in the payday-lending environment, recent work by Melzer (2011) has found that access to payday lenders actually exacerbates debt and bill repayment. This suggests that lenders are potentially able to extract excessive rents from some households. ${ }^{16}$

A full empirical investigation of these alternative hypotheses is challenging, as they often have similar implications as the efficiency view discussed in section 4.2.3. For example, if these products were used to deter recognition of losses and lower the market perception of their risk, we would expect a high concentration of deferred payment/amortization mortgages among less creditworthy borrowers. But according to the efficiency view, we should also see a high concentration of such products among less creditworthy borrowers. However, as we discuss in the next section, there is some evidence that these new forms of lending, coupled with growth in private label securitization, may have adversely affected the incentives of some market participants.

\subsubsection{Did the Changed Nature of Financing Affect \\ Financial Intermediation?}

Did the dramatic changes in the nature of lending impact the behavior of agents engaged in intermediation? General theories of financial intermediation argue that banks help channel resources from savers to users of capital. However, to be able to do so, they must be provided adequate incentives - in

15. See Landier, Sraer, and Thesmar (2010) for discussion of this argument.

16. For a theoretical model of poorly informed borrowers and predatory lending, see Bond, Musto, and Yilmaz (2005). 
part through the illiquidity of long-term investments on their balance sheet. However, securitization changes the lending framework from "originate and hold" to "originate and distribute," and increases the distance between a home owner and the ultimate bearer of the mortgage's risk. A loan sale to an investor results in information loss: some characteristics of the borrower that are potentially observable by the originating lender are not transmitted to the final investor. Since the price paid by investors depends only on verifiable information transmitted by the lender, this process could introduce a moral hazard problem: the lender originates loans that rate highly based on the characteristics that affect its compensation, even if the unreported information implies a lower quality. ${ }^{17}$ It is possible, of course, that regulatory oversight, reputational considerations, or sufficient balance sheet risk may prevent moral hazard on the part of lenders. Understanding the effects of existing securitization practices on screening is thus an empirical question.

How would one detect changes in lenders' origination incentives? In general, the quality of a mortgage loan is a function of both hard and soft information that the lender can obtain about the borrower (see Stein 2002). Hard information, such as a borrower's FICO credit score, is easy to verify; conversely, soft information, such as the borrower's future job prospects, is costly to verify. In the absence of securitization, a lender should internalize the benefits and costs of acquiring both kinds of information and adequately invest in both tasks. With securitization, hard information is reported to investors; soft information, which is difficult to verify and transmit, remains unreported. Investors therefore rely only on hard information to judge the quality of loans. This may eliminate the lender's incentive to collect and evaluate soft information. Consequently, conditional on observable borrower and loan characteristics, borrowers that receive loans may become worse along the soft information dimension as the ease of securitization increases. Therefore, by comparing the default rates, conditional on hard information (observables), one can infer the changes in lenders' screening effort on the margin of soft information.

We now discuss evidence that suggests that subprime securitization did in fact impact lenders' screening incentives. Most of the work discussed here surveys our own work but we will also discuss other evidence in the literature that supports these arguments.

\section{Evidence from Keys, Mukherjee, Seru, and Vig}

In Keys et al. (2010a, henceforth KMSV), the authors asked whether increased access to secondary mortgage markets affected whether lenders were willing to originate loans and the quality of those loans. Making a

17. The same tension exists in the multitasking framework of Holmstrom and Milgrom (1991): an agent compensated for specific tasks ignores other tasks that also affect the payoffs of the principal. 
causal claim requires isolating differences in channels that impact lender behavior and loan outcomes that depend on securitization but are independent of contract and borrower characteristics. The authors used a rule of thumb in the subprime market that generated an exogenous increase in ease of securitization of loans around a particular credit score. This allowed them to identify whether an increase in the ease of securitization had any impact on lenders' screening effort.

Keys et al. identified a rule of thumb in the nonagency investor market related to credit scores, based originally on Fannie and Freddie guidelines. A FICO score above 620 was considered "strong," whereas scores below 620 were perceived as lower quality and deserving of increased scrutiny. Although these GSE guidelines did not apply to the nonagency securities market, whether loans had FICO scores above or below 620 became a commonly used summary statistic in securities prospectuses. Keys et al. argued that adherence to this cut-off by investors (e.g., investment banks, hedge funds), generated an increase in demand for securitized loans just above the credit cut-off relative to loans below this cut-off. This "ease of securitization" can be measured on several dimensions, such as the number of loans securitized, the securitization rate (conditional on origination), or the time it takes a lender to sell a loan.

There are a number of additional ways to measure ease of securitization and establish that there was a systematic difference around FICO = 620 for low documentation loans, the most information-sensitive type of loan being originated. Figure 4.14, part A, presents the distribution of low documentation securitized subprime loans by individual FICO score around the FICO of 620 threshold. The figure shows that there were nearly twice as many loans securitized just above 620 than just below it. An alternative way of evaluating this changed ease of securitization is by examining the conditional securitization rate; that is, conditional on a lender originating a loan, the probability that it is sold. In part B of figure 4.14, KMSV show that low documentation loans originated with FICO scores just above 620 are significantly and discontinuously more likely to be sold than those below 620. Finally, another measure of how "liquid" a loan is the speed with which the loan is sold. If a loan is sold quickly, that frees up lenders' capital requirements and also reduces their "warehousing" risk. Part C shows that low documentation loans just above 620 were sold to the private market over one month faster than loans below the 620 threshold. Thus from the lenders' perspective, if two identical borrowers applied for a low documentation loan, but one had a credit score of 619 and the other a score of 621 , the lender knew the ease of selling was higher above FICO $=620$.

The next figure, figure 4.15 , shows that this differential "ease of securitization" had a direct impact on lenders' screening decisions. Because investors purchase securitized loans based only on hard information, the cost of collecting soft information is internalized by lenders to a lesser extent when 


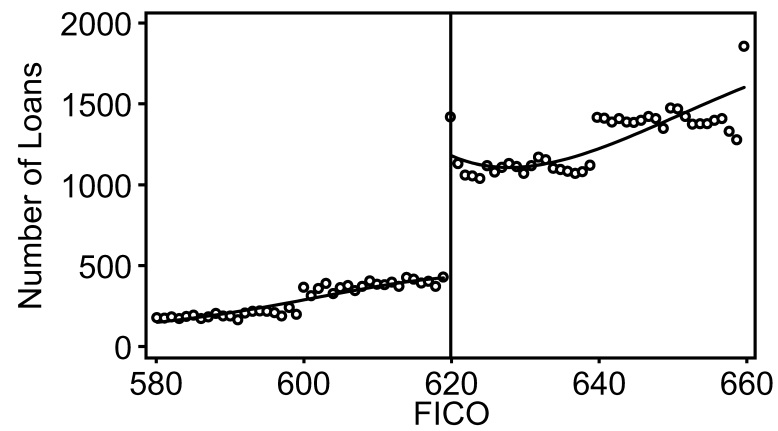

$B$

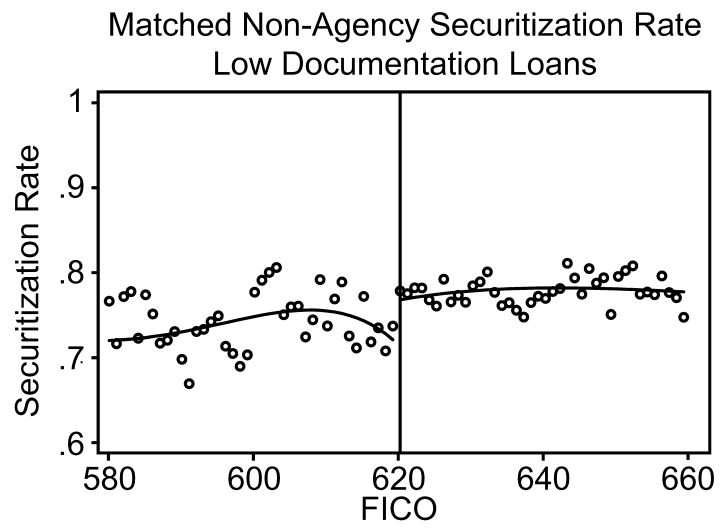

C

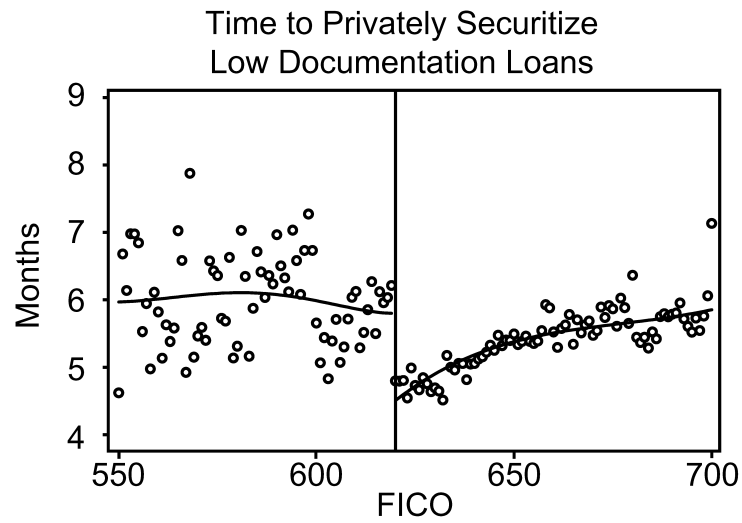

Fig. 4.14 Ease of securitization of private low documentation loans (2001-2006)

Notes: Part A presents the distribution of low documentation securitized subprime loans in the LPS database originated between 2001 and 2006. Part B shows the securitization rate of low documentation loans in the LPS database originated between 2001 and 2006. Propensity Score reweighting is used to attribute unsold loans to the agency or nonagency market. Part $\mathrm{C}$ depicts the average time it takes for loans in the LPS database originated between 2001 and 2006 to be securitized to the private nonagency market. The longer it takes for a loan to be securitized, the costlier it may be for the bank, due to either the opportunity cost of capital or risk of loan delinquency. 
Matched Non-Agency Delinquency Rate

Low Documentation Loans

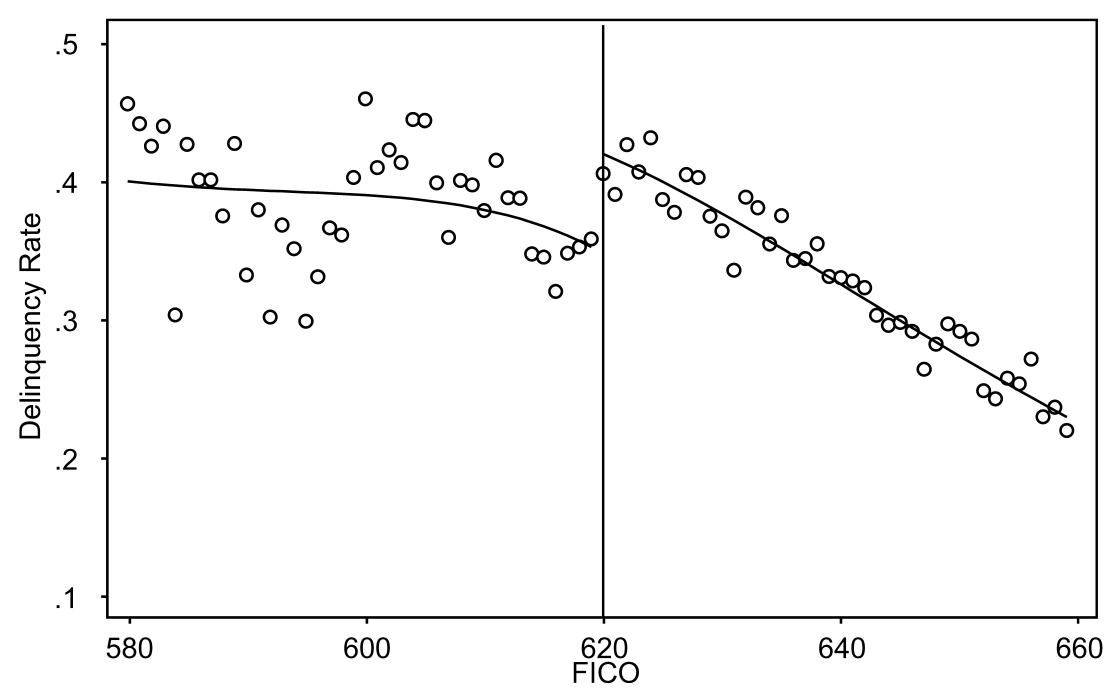

Fig. 4.15 Delinquency rate of private low documentation loans (2001-2006)

Notes: This figure shows the 60+ day delinquency rate for low documentation loans sold to the private market in the LPS database originated between 2001 and 2006. Propensity score reweighting is used to assign unsold loans to the agency or nonagency market based on observable loan characteristics.

screening borrowers at $620+$ than at $620-$. Therefore, by comparing loan portfolios on either side of the credit score threshold, one can assess whether differential access to securitization led to changes in lenders' decisions to offer these loans to consumers with nearly identical risk profiles. Low documentation subprime loans just above 620 were significantly more likely to default than those loans just below 620. Thus differences in the performance of these loans (differential screening) can be attributed to differential access to the secondary mortgage market.

Keys, Seru, and Vig (2012) also show that lenders had private information about these loans that was not provided to investors and differed systematically around $\mathrm{FICO}=620$. In particular, using data from an anonymous large subprime lender (who went bankrupt during the subprime bust), they find that in this lender's pool of originated loans, there are more self-employed borrowers just above 620 than just below 620. These borrowers have more variable income and were likely greater credit risks than borrowers steadily employed by firms. However, despite the fact that this information was maintained in the lender's database, and potentially used in their internal underwriting process, this information was not transmitted to investors purchasing these loans. Exploring the time-series relationship, they further find that 
variation in access to the secondary market is strongly related to variation in screening the low documentation subprime market. In short, there are no samples or environments where differences in default around the cut-off were not related to differences in the ease of securitization. ${ }^{18}$

This evidence can be interpreted as suggesting that providing more documentation (in the case of full documentation loans sold to the non-GSEs), or additional mechanisms to monitor and constrain lenders (in the case of the GSEs, underwriting software, reps and warranties, and reputation risks all fall into this category) may have limited the amount of soft information available for lenders to differentially screen on. However, it is also worth noting that although the Keys et al. (2012) methodology does not uncover differential loan performance in some markets, this does not necessarily mean that lenders were not influenced by the ease of access in other markets.

\section{Broader Patterns in the Market and Other Evidence}

While work in KMSV focused on establishing the causal link between securitization and screening, there are several patterns in the broader market that suggest this link was not restricted locally around FICO of 620. To evaluate broader effects, it is useful to note what the increased securitization of subprime loans implies for lender behavior. Securitization increases the distance between lenders and investors, making it difficult to contract on every possible variable (see Stein 2002). In particular, only hard, easily verifiable information is reported to investors and the soft information, which is difficult to verify and transmit, remains unreported. Therefore, due to the greater distance between originators and investors, the interest rate on new loans may depend increasingly on hard information reported to the investor. Also, due to the loss of soft information, the interest rate on a loan may become an increasingly poor predictor of loan performance. ${ }^{19}$

18. In Keys et al. (2010a), the possibility that the 620 rule of thumb was in fact unrelated to securitization, but instead reflected lenders choosing an optimal screening cut-off, was considered, tested, and rejected. In that paper, the authors used changes in antipredatory lending laws in New Jersey and Georgia as a natural experiment to vary access to secondary markets. During periods when lenders were constrained from easily accessing nonagency securitization markets, the differences around the 620 threshold in both loan sales and loan performance disappeared. However, the differences reappeared once the laws were weakened and the originateto-distribute model was up and running again in these states. Support of the optimal lender rule of thumb has been provided by Bubb and Kaufman $(2009,2011)$, who claim to find differences in default rates without any differences in the ease of securitization in the non-Jumbo market. Keys, Seru, and Vig (2012) show that Bubb and Kaufman's results are due to their combining loans from different secondary markets into one analysis. When analyzed separately, even using Bubb and Kaufman's data set and definitions, the same patterns emerge: differences in loan performance and differences in the ease of securitization around FICO of 620 for low documentation loans sold to nonagency investors. There are no differences in loan performance at the threshold for any other types of loans.

19. With securitization, there is an information loss, since the lender offers the same interest rate to both good and bad types of borrowers at the same interest rate (see Rajan, Seru, and Vig 2010). As a result, in a high securitization regime, the interest rate becomes a noisier predictor of default for the loan pool. 
Rajan, Seru, and Vig (2010) provide evidence for both these predictions. In particular, using a large database on securitized subprime loans across different US lenders, they find that over time the interest rate on new loans relies increasingly on a small set of variables. Specifically, the $R^{2}$ of a regression of interest rates on borrower FICO credit scores and loan-to-value (LTV) ratios increases from 9 percent for loans issued in the period 1997 to 2000 to 46 percent for 2006 loans. Further confirmation comes from the dispersion of interest rates; conditioning on the FICO score, the standard deviation of interest rates on new loans shrinks over time. Second, Rajan et al. show that with increased securitization the interest rate becomes a worse predictor of default likelihood on a loan. In particular, the pseudo- $R^{2}$ of this logit regression declines with securitization, suggesting that the interest rate loses some of its ability to predict loan defaults. In related work, Loutskina and Strahan (2011) find that as lenders sought a national presence, they lost any geographic informational advantages they previously had acquired, and no longer performed "informed" underwriting based on local (soft) knowledge of markets.

There are several other papers that also suggest a link between changed nature of supply of credit due to subprime securitization and the quality of loans that were originated. First, Mian and Sufi (2009) investigate causes of the expansion in subprime mortgage credit and find evidence consistent with an increase in lending supply and defaults that are correlated with securitization activity. Using zip code-level data, they find that places that had greater securitization rates were places in which subprime credit increased most dramatically. In a similar spirit, Purnanandam (2011) uses the exogenous shut down of the private label securitization market to evaluate the quality of loans that were originated by lenders who intended to securitize them, and compare these to loans that were not intended to be securitized. His evidence suggests that banks active in pursuing an originate-to-distribute model of lending did not expend as many resources in screening their borrowers.

Next, Jiang, Nelson, and Vytlacil (2010) use data from one of the top subprime lenders in the United States and a similar identification strategy as KMSV to find that increases in securitization reduced the lender's origination standards. In addition, the paper shows that observing ex post default patterns on unsold loans and comparing them with default patterns of sold loans to make inferences on the ex ante connection between securitization and screening are misplaced. The reason is that most subprime lenders originated all loans with intent to sell and loans that were ex post unsold were of lower quality; for instance, they suffered an early payment default. ${ }^{20}$

Finally, Nadauld and Sherlund (2009) use the timing of a reduction in Securities and Exchange Commission (SEC)-mandated capital requirements

20. A similar point was also made in KMSV (2010b). 
to identify the impact of intermediation on increases in subprime credit. They find that when capital requirements were reduced, more mortgage credit was supplied to neighborhoods with high house price appreciation and to subprime borrowers. The results corroborate the view that increased access to the secondary mortgage market weakened lenders' screening incentives.

\section{Were These Patterns Related to Agency Conflicts in the Supply Chain?}

While most of the work just discussed evaluates whether there was a change in loan quality when the nature of financing changed, it does not assess what parts of the securitization chain were affected. As discussed earlier, there are several agents involved in the supply chain of credit, from brokers and lenders who originate the loan, to issuers and underwriters who package the loans before they are sold to investors. As discussed in detail in Ashcraft and Schuermann (2008), there are potentially multiple agency conflicts between various participants in the supply chain of credit that can affect the quality of loans originated. While this narrative is convincing, it is a narrative that is generally difficult to test empirically.

The reason that Ashcraft and Schuermann (2008) and earlier work were not able to empirically evaluate the changes in behavior of these agents in response to changes in ease of securitization is that it requires detailed data that was not easily available. We now present some suggestive evidence based on new data that is consistent with agent incentives playing an important role in loan performance. We also discuss several new papers in the literature that have also used similar data sources and provide evidence that confirms the presence of agency conflicts in the supply chain.

To conduct our analysis, we need information beyond what is provided in the databases we listed earlier. In particular, we need to collect information on the composition of originators contributing to a mortgage pool as well as information on other agents in the supply chain of credit such as issuers and underwriters of the pool. This information is available in the prospectus document of a deal. However, reading all deal prospectuses is a time-consuming task. We therefore randomly sample mortgage-backed securities (MBS) deals over the period 2004 to 2007 and cover roughly 1,200 mortgage pools spread across these years. We restrict attention to these years since the availability of prospectuses of mortgage pools in the earlier periods is limited.

Using the information available in these deals we construct a variable that we employ in our analysis. In particular, we use information on the originators who contribute loans to a deal. Most prospectuses list information on originators as well as their contribution to the pool. This allows us to construct a variable that reflects whether a pool has relatively higher number of "small originators" contributing to it. We use this measure to test whether 
the performance of loans in a pool is reduced if it is more difficult to monitor the incentives of agents originating the risk. More specifically, we construct an indicator variable ("minor contributors") that takes a value of 1 if the pool consists of more than one lender that is not a major contributor. We then evaluate the performance of the same vintages of loans that are securitized by pools with or without these minor contributors.

Panel A of table 4.2 presents the results of this regression. The dependent variable here is the proportion of loans (dollar-weighted) in a given

Table 4.2 Delinquency in privately securitized mortgage pools and characteristics
of agents in the supply chain

\begin{tabular}{lcccc}
\hline \multicolumn{5}{c}{ A. Different characteristics of agents in supply chain of credit } \\
\hline & $\begin{array}{c}\% 0+ \\
(1)\end{array}$ & $\begin{array}{c}\% 90+ \\
(2)\end{array}$ & $\begin{array}{c}\% 60+ \\
(3)\end{array}$ & $\begin{array}{c}\% 90+ \\
(4)\end{array}$ \\
\hline Subordination level & $0.001^{* * *}$ & $0.002^{* * *}$ & $0.001^{* * *}$ & $0.002^{* * *}$ \\
& $(11.03)$ & $(8.01)$ & $(11.03)$ & $(8.19)$ \\
Dummy (minor originators) & & & $0.003^{* *}$ & $0.008^{* * *}$ \\
& & & $(2.42)$ & $(3.58)$ \\
Observations & 832 & 832 & 832 & 832 \\
$R^{2}$ & 0.24 & 0.18 & 0.25 & 0.19 \\
Other controls & Yes & Yes & Yes & Yes \\
Vintage fixed effects & Yes & Yes & Yes & Yes \\
\hline
\end{tabular}

B. Originators with different regulatory oversight

\begin{tabular}{lcc}
\hline & $\begin{array}{c}\% 60+ \\
(1)\end{array}$ & $\begin{array}{c}\% 90+ \\
(2)\end{array}$ \\
\hline Subordination level & $0.001^{* * *}$ & $0.002^{* * *}$ \\
& $(11.03)$ & $(8.19)$ \\
Dummy (originators largely & $-0.002^{* *}$ & $-0.004^{* *}$ \\
nonbank) & $(2.30)$ & $(1.97)$ \\
Observations & 832 & 832 \\
$R^{2}$ & 0.25 & 0.19 \\
Other controls & Yes & Yes \\
Vintage fixed effects & Yes & Yes \\
\hline
\end{tabular}

Notes: This table reports regressions that relate the quality of the pool with various pool-level characteristics and characteristics of agents originating the loans. The dependent variable in each regression is the dollar volume of loans that are sixty-day delinquent or ninety-day delinquent within twenty-four months of origination. The regressions include controls for average pool FICO, interest rate, LTV, the proportion of loans that are low documentation, and the proportion of loans that are ARM. In addition, we also include origination vintage time effects.

$* * *$ Significant at the 1 percent level.

**Significant at the 5 percent level.

*Significant at the 10 percent level. 
mortgage pool that became late on their payments by sixty or ninety days within twenty-four months of originating the loan (percent $60+$ or percent $90+)$. In the first two columns, we examine if the baseline results of the pools for which we have complete information (830 out of 1,200) seem sensible. In particular, we include the subordination level of the pool-the percent of lower tranches that are affected before the top tranches of the pool are affected - an indication of risk. As is expected, we find that subordination levels are positively related to the subsequent quality of the pool-that is, there is a higher cushion for deals that have a higher proportion of risky loans. In these regressions we include other pool-level variables that measure the quality of the collateral (e.g., average pool FICO, LTV, interest rates, percent low documentation loans, percent ARM loans).

In the next set of columns ([3] and [4]), we regress the variable we discussed before and find indeed that pools with more minor lenders contributing loans performed worse. Even though these are admittedly naïve regressions that may not account for other important factors affecting delinquencies, these results are suggestive of agency problems affecting the quality of originations from the securitization chain.

The evidence we provided in this section is consistent with several other studies. First, the findings are broadly in line with KMSV (2009), where the authors used the FICO $=620$ as a source of differential ease of securitization and evaluated which factors alleviated or aggravated differential screening by lenders. In particular, they also find that more stringent broker laws across states - with several states requiring brokers who originate mortgages to post "surety" bonds - are associated with higher quality originations. These findings are also broadly consistent with Jiang, Nelson, and Vytlacil (2009), who find that broker-originated loans for a large subprime lender performed significantly worse than those originated by the bank's own loan officers. Notably, their specification and data allow them to account for several hard information variables that the bank collects but may not pass to investors or data-vendors (beyond those as employed in our analysis). Nevertheless, the finding that loans originated by brokers are of worse quality remains.

Finally, more generally, these results are also consistent with Demiroglu and James (2012), who show that the quality of loans originated in pools that have the same institution undertaking the tasks of originating, sponsoring the deal, as well as servicing the loans tended to be of significantly better quality. This was true both when the authors looked at delinquencies as well as foreclosures of a large number of deals - with effects most pronounced for deals originated during the housing boom.

\section{What about Regulation?}

Did regulation have any bite in alleviating the reduction in lending standards? The subprime mortgage market consists of lenders who perform 
similar tasks - origination and distribution — but are differentially regulated. Deposit-taking institutions (banks/thrifts and their subsidiaries) undergo rigorous examinations from their regulators: the Office of the Comptroller of the Currency, Office of Thrift Supervision, Federal Deposit Insurance Corporation, and the Federal Reserve Board (see Agarwal, Luca, et al. 2012). Non-deposit-taking institutions, on the other hand, are supervised relatively lightly. To evaluate if more oversight led to better underwriting we compare the quality of loans originated by banks and compare them to those originated by nondepository institutions.

To conduct our tests, we classify lenders in our sample into banks, thrifts, subsidiaries of banks/thrifts, and independent lenders. Each loan in the database is linked to an originating lender. However, it is difficult to directly discern all unique lenders in the database since the names are sometimes spelled differently and in many cases are abbreviated. We manually identified the unique lenders from the available names when possible. In order to ensure that we are able to cover a majority of loans in our sample, we also obtained a list of top fifty lenders (by origination volume) for each year from 2001 to 2006, previously published by the publication Inside $B \& C$ Mortgage. Across years, this yields a list of 105 lenders. Using the list we are able to identify some abbreviated lender names, which otherwise we might not have been able to classify. Subsequently, we use Form 10-K proxy statements and lender websites (whenever available) to classify the lenders into two categories - banks, which comprise all lenders that are banks, thrifts, or subsidiaries of banks and thrifts, and independents. An example of a bank in our sample would be Bank of America, while Ameriquest is an example of an independent lender.

In panel B of table 4.2, we examine the performance of the same vintages of loans that are securitized by banks relative to those securitized by independents. In particular, we regress the proportion of loans (dollar-weighted) in a given mortgage pool that became late on their payments by sixty or ninety days within twenty-four months of originating the loan (percent $60+$ or percent 90+). The results in columns (1) and (2) suggest that pools where loans are primarily originated by independent lenders tend to perform better as compared to those where banks primarily originated the loans. While we realize that this is a limited comparison - the characteristics of borrowers, contractual terms, and other institutional features may differ in ways not accounted for by our simple specification and controls - we are provided comfort by the observation that KMSV reached the same conclusion with a superior identification strategy.

These results are consistent with the institutional reasons discussed in Van den Heuvel (2008) where most of the focus of the regulation across institutions was on "balance-sheet" items rather than "off-balance" sheet activities such as subprime mortgage loans that were primarily intended to be securitized and were, therefore, considered as "off-balance" sheet. 


\section{Implications}

The main implication that can be drawn from this line of research is that skin in the game and mechanisms for monitoring and enforcement play an important role in the performance of mortgages, and hence mortgage bonds. In particular, complete documentation of income and assets, as well as the reputation/exclusionary threat by the GSEs to constrain lender behavior, appear to have led to better outcomes than in the private low documentation subprime market. In the absence of these checks on lender strategic behavior, it appears that lenders differentially screened borrowers, and that mechanisms such as retaining a junior portion of the security may provide significant incentives for lenders to conduct more careful screening.

In addition, the results related to state-level variation in broker laws again support the view that agency problems are mitigated in instances where agents involved in the supply chain of credit had more "stakes" involved. These findings are also confirmed when loans were pooled across different lenders - potentially making it harder for the issuer to monitor the quality of the loan pool. Furthermore, the finding that loan pools where the issuer and the underwriter were the same institution had better performance also supports the idea that the participants in the credit chain have differing incentives, and that when aligned can be used to reduce the agency problems and resulting lower quality of the pool.

Our results also have another important implication. They suggest that there is substantial heterogeneity in how the agency conflicts manifest themselves across different types of products. In particular, we find a great deal of heterogeneity across market segments in the ability of lenders to behave strategically. This finding does not necessarily support the view that the Dodd-Frank mandate of 5 percent risk retention is the optimal amount of risk retention in the mortgage market. In some segments of the market, 5 percent may not be enough to strengthen incentives, while in others, retaining a 5 percent portion of the loan pool may be prohibitively costly to fund private label securitizations. Although our results provide broad support for skin in the game, we would need a more complete model of pool performance and information frictions to quantify the optimal level of risk retention for a given type of underlying mortgage asset.

\subsection{The Foreclosure Crisis and the Challenges of Renegotiation}

Since 2007, as the housing crisis unfolded, the number of foreclosures reached unprecedented levels. What was behind the high number of defaults and foreclosures? First, almost by definition, the most important factor was a decline in the level of house prices that put many home owners underwater - that is, those borrowers had a negative amount of equity in their homes. This decline was accompanied by an increase in unemployment and 
a broad economic recession that put additional stress on borrowers' willingness and ability to pay their loans. ${ }^{21}$

In addition, in such an environment one would expect high foreclosure rates on nonagency securitized mortgages since, as discussed before, these loans tended to have higher loan-to-value ratios and were made to riskier borrowers (and more sensitive to systemic risk). Indeed, nonagency securitized mortgages accounted for more than half of the foreclosure starts during the first two years of the crisis, despite their much smaller market share (see Piskorski, Seru, and Vig 2010). However, there was also concern among academics and policymakers that the high foreclosure rate on securitized mortgages might also partly reflect misaligned incentives in origination of these products and its adverse impact on screening and underwriting standards (see section 4.3.2). Furthermore, there was also a concern that several other factors could have impeded effective renegotiation of these mortgages, thereby aggravating the foreclosure crisis. We now discuss some of these reasons in turn.

\subsubsection{Challenges to Effective Renegotiation of Residential Mortgages}

\section{Securitization}

There are compelling arguments that in times of significant adverse macro shocks, debt forgiveness and loan renegotiation can create value for both borrowers and lenders (Bolton and Rosenthal 2002; Piskorski and Tchistyi 2011). However, as of early 2009, the general perception was that there were far too few mortgage modifications performed by lenders and servicers, and that even those that were performed were not effectively helping borrowers avoid losing their homes. This was particularly troubling given the significant deadweight costs of foreclosure due to lack of incentives for borrowers to maintain their homes (see Melzer 2012), as well as negative externalities of foreclosure (see, e.g., Campbell, Giglio, and Pathak 2011).

As most of the early foreclosures occurred among nonagency securitized loans, a debate ensued regarding whether dispersed ownership and potential agency frictions brought about by the securitization of residential mortgages inhibited renegotiation of loans at risk of foreclosure. In the case of a securitized loan, the servicer acts as an agent of the investors and makes the crucial decision of how to handle a delinquent loan: choosing to pursue either a

21. According to the option-theoretic literature, borrowers default on their mortgage when the value of the house falls below the current value of the mortgage (see, among others, Kau, Keenan, and Kim [1994] and Deng, Quigley, and Van Order [2000]) This may imply that the optimal default trigger is such that the borrower has negative equity measured as ratio of the loan balance to the current market value of the house. This theory assumes that the borrower has full access to credit markets for unsecured credit such that default is unaffected by liquidity considerations and income fluctuations. We note, however, that in a setting in which the borrower values the home more than its "market" value and/or faces default costs, the default can be triggered by liquidity shocks. 
foreclosure or a modification of the mortgage. A number of commentators and academics have argued that servicers' financial incentives, legal constraints and uncertainty in servicers' contracts, and coordination problems among multiple investors may have inhibited renegotiation of securitized loans, thereby aggravating the foreclosure crisis. ${ }^{22}$

Existing research has been consistent with this view. Piskorski, Seru, and Vig (2010) examine whether securitization impacts loan servicers' renegotiation decisions, focusing on their choice to foreclose a delinquent loan. Conditional on a loan becoming seriously delinquent, they find a significantly lower foreclosure rate associated with bank-held loans when compared to similar securitized loans. Across various specifications with numerous controls and origination vintages, they find that the foreclosure rate of delinquent bank-held loans is 3 to 7 percent lower in absolute terms (13 to 32 percent in relative terms).

They further confirm these results in a quasi-experiment that exploits plausibly exogenous variation in securitization status of a delinquent loan. In particular, the quasi-experiment involved using repurchase clauses (either due to early pay defaults or due to violations of reps and warranties) that legally obligate originators to purchase back any securitized loans that become delinquent, typically within ninety days of the loan being securitized. Piskorski, Seru, and Vig (2010) use this feature to construct two groups: securitized loans that become delinquent just before ninety days and were taken back by the originator and serviced as if the loan was bank-held (treatment group); securitized loans that become delinquent just after ninety days and continued to be serviced as securitized loans (control group). Since both types of loans are securitized to start with, the repurchase feature allows them to circumvent any ex ante selection on unobservable concerns by providing plausibly exogenous variation in the securitization status of a delinquent loan. By comparing the foreclosure rates of distressed loans in the treatment and control groups, they are able to show that securitization induced foreclosure bias in the decisions of lenders and servicers.

While the foreclosure results of Piskorski and colleagues are consistent with securitization impacting renegotiation, the authors did not have "direct" data on the renegotiation decisions of lenders. ${ }^{23}$ However, this data was collected by the Office of the Comptroller of the Currency. Trends in the OCC data confirm that results Piskorski, Seru, and Vig (2010) are driven by differences in lenders' renegotiation decisions-renegotiation rates were higher for bank-held loans, and these renegotiations were both more

22. See, among others, Gelpern and Levitin (2009); Mayer, Morrison, and Piskorski (2009); Posner and Zingales (2009); White (2009a, 2009b).

23. These results also are consistent with Gan and Mayer (2006) and Ambrose, Sanders, and Yavas (2011). These papers find that servicers change their behavior toward renegotiations depending on whether they own a first-loss position for the loans they service. 
aggressive (e.g., had a higher principal reduction) and more effective (had a lower redefault rate conditional on receiving a modification).

While the OCC data is suggestive, it is not conclusive. The data provides trends and averages without adequately accounting for different loan and borrower. This deficiency was overcome in Agarwal et al. (2011a, 2011b), who use data on direct renegotiations. Exploiting within-servicer variation in these data, they find that bank-held loans are more likely to be modified than comparable securitized mortgages ( 4.2 to 5.8 percent in absolute terms). Moreover, they establish that these differences in renegotiation rates explain the lower foreclosure rate of bank-held loans relative to comparable securitized mortgages. They also show that modifications of bankheld loans are more efficient. These findings have subsequently been also confirmed independently in a recent paper by Zhang (2011). The paper also discusses why using "indirect imputation" methods to infer renegotiations had led to biased inferences by some studies such as Adelino, Gerardi, and Willen (2010) (also see the discussion in Piskorski, Seru, and Vig 2010).

Finally, Agarwal, Zhang, et al. (2011), use an alternative strategy to reveal another manner in which securitization induces impediments to renegotiation. In particular, they document that when there is a difference in the ownership of liens on the house (second and first liens are sold to different sets of investors), the likelihood of liquidation is higher by 3.6 percent points in six months ( 60 percent in relative terms). They also find that the efficiency of renegotiation on a given loan (in terms of redefault rates) is lower for loans that suffer more from this problem.

Overall, this literature supports the view that frictions introduced by securitization created significant challenges to effective renegotiation of residential loans. While most of the studies just described focus on establishing that securitization introduced impediments in renegotiation during the early phase of the crisis period, there is no evidence on how these effects were spread heterogeneously across parts of the United States. We provide some evidence to this end by focusing on one particular aspect - the impact of foreclosure laws. In the United States, many states protect borrowers by imposing restrictions on the foreclosure process. This may make it difficult for servicers to foreclose in states where these laws make it harder to foreclose (i.e., in creditor unfriendly states). We investigate if these laws interacted with the impediments that securitization imposed on the renegotiation process.

While we lack data on direct renegotiations, we use foreclosure rates on distressed loans as a proxy. As previous research confirms, this is a reasonable variable if one is interested in capturing renegotiations on distressed loans. We follow Pence (2006) and classify states into those where foreclosure laws are creditor friendly (called "tough" states) and for states where these laws are creditor unfriendly (called "weak" states).

Table 4.3 reports the estimates from a regression evaluating the impact of securitization on foreclosure rates of distressed loans in the two different 


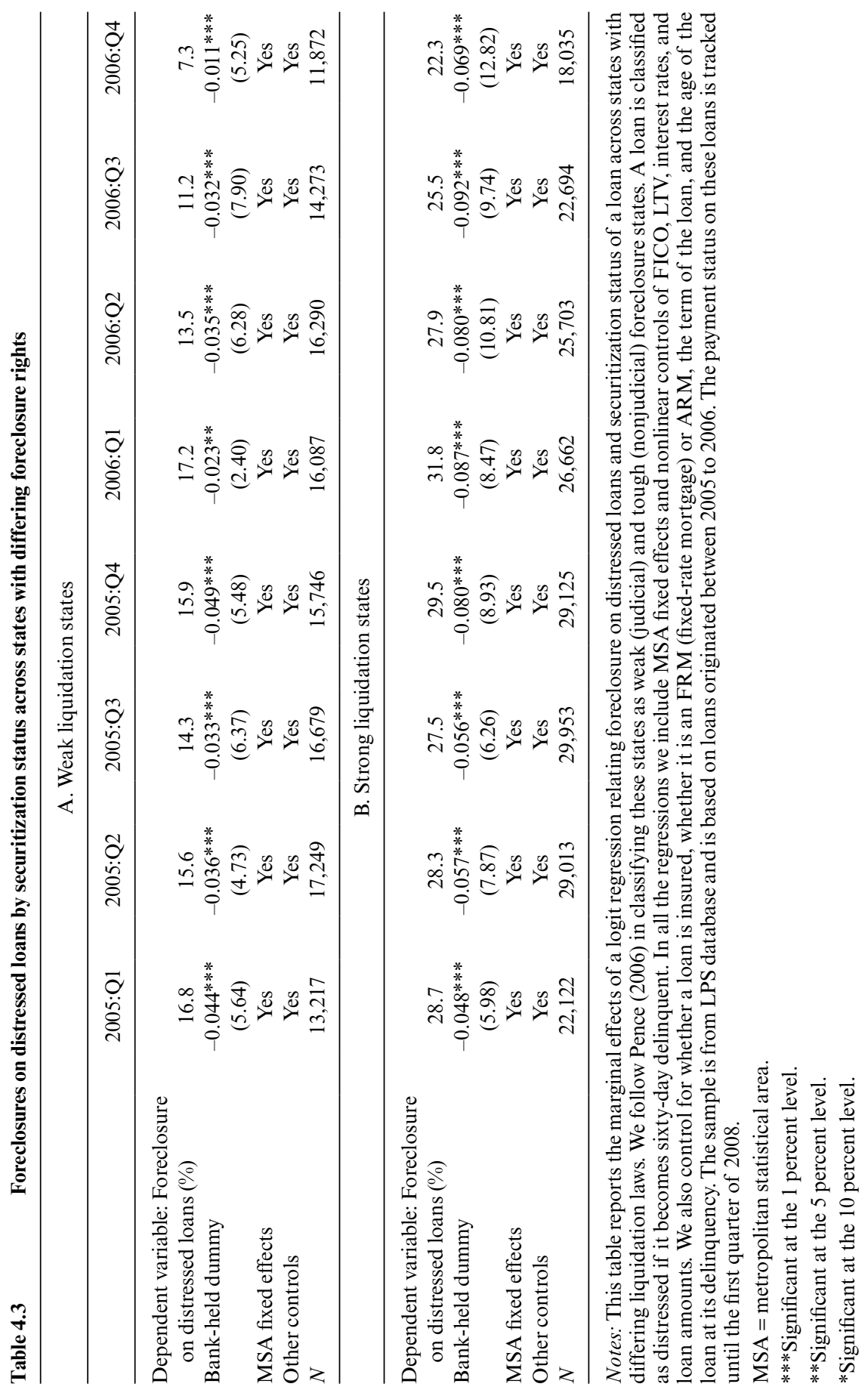


sets of states. On average, delinquent loans in states with tough liquidation laws are about twice as likely to default as delinquent loans in states with weak liquidation laws ( 28 percent to 14.2 percent). This is consistent with the patterns reported in Mian, Sufi, and Trebbi (2011), who find higher foreclosure rates in tougher states as well. More importantly for our purpose, we find that, conditional on being seriously delinquent, the difference in the foreclosure rates between securitized and portfolio loans is much higher for those loans that are originated in states with creditor-friendly laws; that is, states that allow for quick foreclosure and house repossession.

Although we account for a number of observable characteristics, it is possible that these differences are driven by some unobservable factors. However, we note that these correlations are consistent with basic economic arguments that support the view that creditor friendly rights are beneficial to both lenders and borrowers, at least from the ex ante perspective (by facilitating the provision of credit). Our evidence suggests that strong creditor rights can also have some negative consequences by exacerbating the renegotiation frictions imposed by securitization. It is possible that the magnitude of the current crisis was not fully anticipated by investors and borrowers and so they did not provision for this contingency. Consequently, less creditor friendly laws potentially provided additional time to borrowers, investors, and government to intervene in order to change the nature of mortgage servicing.

\section{What about Other Factors?}

While the securitization of mortgages did impact renegotiation rates, it is clearly not the only factor impeding renegotiations; the renegotiation rate on delinquent bank-held loans is not 100 percent. What other factors were crucial in impeding renegotiations? We now discuss some of the salient factors that have emerged in the literature and also provide some evidence that supports their importance.

\section{Identifying "Eligible Borrowers"}

An important challenge in designing cost-effective mortgage modification programs is how to develop eligibility criteria that efficiently identify home owners who are likely to default unless they receive help. In practice, it is difficult to identify these at-risk homeowners. Although millions of home owners are "underwater" and therefore at risk of default, the majority of these home owners are still making timely mortgage payments and may continue doing so without receiving a mortgage modification. ${ }^{24}$ It could be quite costly to extend benefits to all of these underwater home owners.

One possible solution to this problem is to extend benefits only to home

24. See, for example, Stevens (2011). 
owners who are delinquent. ${ }^{25}$ This approach, however, could induce home owners to default in order to obtain modification benefits even though they would not have defaulted otherwise. The extent of such "strategic" behavior crucially depends on whether costs of delinquency are sufficiently high to deter it for most home owners. In addition, moral considerations or bounded rationality may decrease a borrower's ability or willingness to behave strategically (see, e.g., Guiso, Sapienza, and Zingales 2009; Bhutta, Dokko, and Shan 2010).

But what is the extent of strategic borrowers in the economy and how could they be identified? We now provide some evidence that tries to identify such "strategic defaulters" using additional borrower payment data from credit bureaus. The analysis suggests that the rate of strategic defaults did increase dramatically as house prices decreased.

In classifying borrowers as "strategic" or not, we took all the loans in the BlackBox database. We then matched borrowers who took these loans to credit bureau data from Equifax and obtained the entire payment history of these borrowers across different credit products. We define a borrower as "strategically" defaulting if the borrower stops paying a delinquent mortgage loan (i.e., a borrower who became sixty-day delinquent for the first time and remained seriously delinquent), while concurrently paying on all nonHELOC (home equity line of credit) revolving debt in the next six months. ${ }^{26}$

Figure 4.16 shows the fraction of borrowers who become sixty-day delinquent for the first time, classified as "strategic defaulters." As we can observe, strategic default was rare prior to the crisis. Less than 2 percent of borrowers fall in this category among the mortgages that went delinquent in mid-2005. This is not surprising, as house prices were still increasing. In contrast, by mid-2010 close to 20 percent of borrowers can be classified as strategic defaulters. ${ }^{27}$

Figure 4.17 shows the fraction of "strategic defaulters" by origination vintage. Again, the fraction of strategic defaulters is low for early origination vintages, as these borrowers experienced significant house price appreciation. However, this fraction increases over time, as was shown earlier.

25. For example, a number of modification programs have made benefits available only to home owners who failed to make at least two monthly mortgage payments. See Citigroup (2009).

26. Note that we are not ascribing a moral judgment on this behavior, as it may be optimal for a household to repay certain debts while ignoring others. Households face a dynamic debt service problem and maintaining some access to unsecured credit - paying off credit card bills first, for instance, while missing four straight mortgage payments, may be an optimal choice given the delays in the foreclosure process. While some call this behavior "ruthless," one could just as easily also call it "optimizing" behavior.

27 . We also note that in mid-2005 close to 20 percent of newly delinquent borrowers could exit their delinquency by paying off their loans (e.g., selling the house or refinancing the mortgage). This fraction drops to virtually 0 percent by 2009 . This is hardly surprising, as by this year the private refinancing market collapsed and house prices suffered significant decline. 


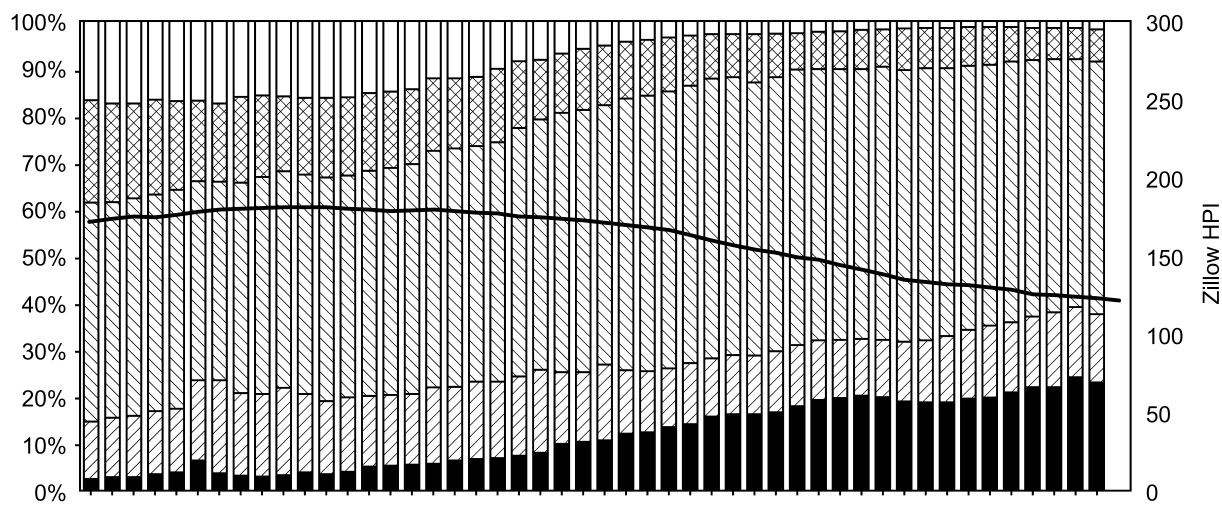

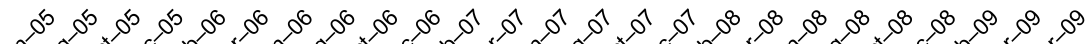

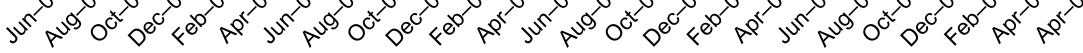
Month of first $60 \mathrm{dpd}$

"Strategic Defaults" (Including HELOC Delinquencies) $\square$ No revolving delinquencies but don't roll straight into 180dpd $\triangle$ Have revolving delinquencies

$\triangle$ No revolving accts on file

Pay off within 6 mos

—Avg Zillow HPI

\section{Fig. 4.16 Strategic defaults over time}

Notes: This figure presents the borrowers defined to be "strategically defaulting" over time. A borrower is defined as doing so if the mortgage loan progressively goes from its $60 \mathrm{dpd}$ for the first time to $180 \mathrm{dpd}$, while concurrently making payments on all non-HELOC revolving debt. In this chart, "Pay off within 6 mos" takes precedence over other categories, so, for example, if a loan pays off and also has no revolving accounts on file, it will be classified as paid off.

Moreover, the shorter the loan age, the bigger is the fraction of strategic defaulters, reaching more than 10 percent for loans originated in 2006 and 2007. In figure 4.18 we also plot the fraction of strategic defaulters as a function of house price change in their location. The areas with the largest house price declines have the largest share of strategic defaulters. In the areas where house prices experienced more than a 40 percent decline in prices from the peak, strategic defaulters account for about 20 percent of all mortgage defaults.

To investigate this further, in unreported tests we estimate a regression where the dependent variable is whether or not the delinquency is classified as a strategic default (as defined before). The loans used in the regressions are all loans originated between 2003 and 2007 that roll sixty days past due (dpd) for the first time with nonmissing control variable information. We find that the probability of a default being strategic increases with origination year. We also augment this specification and also include the usual loan level controls such as interest rate, origination FICO and LTV, documentation type, and loan type. We further find that having a 100-point increase in origination FICO increases the likelihood of a default being strategic by 4.38 percent. That borrowers with higher creditworthiness are more likely to engage in strategic defaults is consistent with survey evidence in Guiso, 


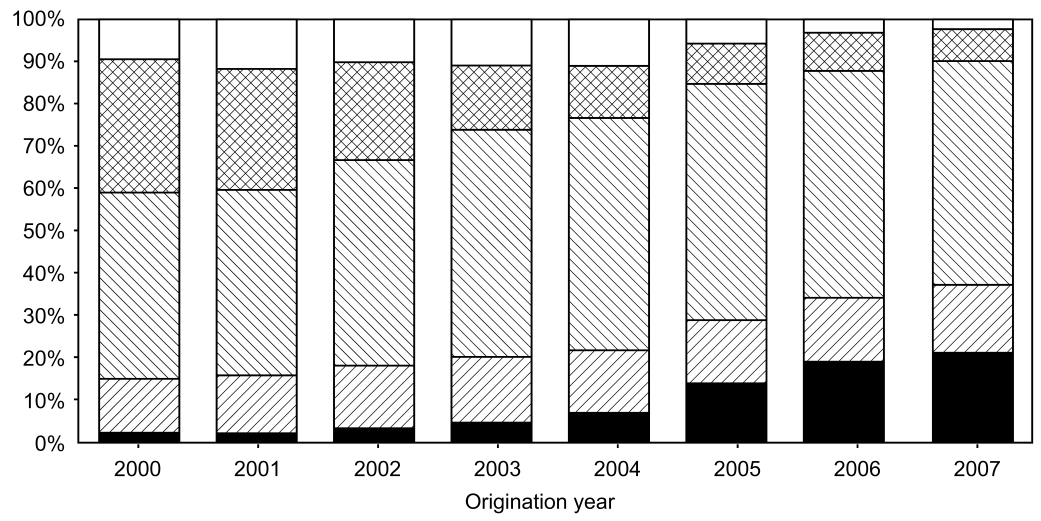

"Strategic Defaults" (Including HELOC Deliquencies) $\square$ No revolving delinquencies but don't roll straight into 180dpd $\triangle$ Have revolving deliquencies $\triangle$ No revolving accts on file

Pay off within 6 mos

\section{Fig. 4.17 Strategic defaults by origination vintage}

Notes: This figure presents the borrowers defined to be "strategically defaulting" over time for various vintages. A borrower is defined as doing so if the mortgage loan progressively goes from its $60 \mathrm{dpd}$ for the first time to $180 \mathrm{dpd}$, while concurrently making payments on all nonHELOC revolving debt. In this chart, "Pay off within 6 mos" takes precedence over other categories, so, for example, if a loan pays off and also has no revolving accounts on file, it will be classified as paid off.

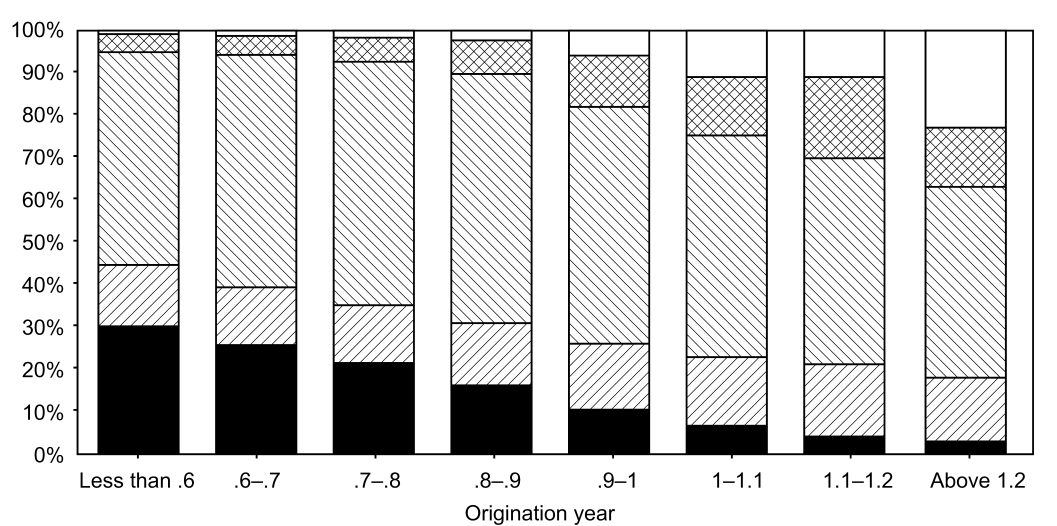

"Strategic Defaults" (Including HELOC Delinquencies) $\square$ No revolving delinquencies but don't roll straight to 180dpd $\triangle$ Have revolving delinquencies

$\triangle$ No revolving accts on file

Pay off within 6 mos

\section{Fig. 4.18 Strategic defaults by change in HPI}

Notes: This figure presents the borrowers defined to be "strategically defaulting" over time across regions with differential HPI changes over the period 2001 to 2009. A borrower is defined as doing so if the mortgage loan progressively goes from its $60 \mathrm{dpd}$ for the first time to $180 \mathrm{dpd}$, while concurrently making payments on all non-HELOC revolving debt. In this chart, "Pay off within 6 mos" takes precedence over other categories, so, for example, if a loan pays off and also has no revolving accounts on file, it will be classified as paid off. 
Sapienza, and Zingales (2011). Likewise more levered loans (those with higher LTV) are more likely to display strategic default. We also add in a variable that identifies the house price change from origination, equal to current OFHEO (Office of Federal Housing Enterprise Oversight) HPI/ origination HPI (housing price index). The results reveal that if the HPI of a property decreases compared to the origination HPI, then the likelihood of the default being strategic becomes greater. For example, a 20 percent decrease in the house prices since loan origination increases the likelihood of strategic default by almost 5 percent (more than a 50 percent increase in relative terms).

Overall, these are sizable magnitudes of borrowers who are current on revolving debt but remained seriously delinquent on their mortgage in the six straight months. We also note that our definition of "strategic default" is very stringent. If we were to take other definitions - for example, the fraction of borrowers who become seriously delinquent at some point of time on their mortgage while being subsequently current on their revolving debt - the proportion of such borrowers is much higher. Figure 4.16 indicates this clearly. It shows that among borrowers who became seriously delinquent for the first time in April 2009, almost 40 percent were current on their revolving accounts during the next six months.

The previous evidence suggests that a sizable fraction of "underwater" borrowers who defaulted on their loans appear to be not financially constrained and so had discretion of whether or not to default on their mortgages. ${ }^{28}$ We now highlight a related issue that is faced by lenders designing a renegotiation program - the impact of the program in inducing strategic behavior by an additional set of borrowers. In particular, mortgage modification programs targeted at delinquent borrowers may encourage some borrowers who would otherwise stay current on their mortgage to default in order to obtain the benefits of a modification.

This tension underlying any modification initiative is illustrated in recent research by Mayer et al. (2011). The paper provides direct evidence on whether home owners respond strategically to news of mortgage modification programs. The authors exploit plausibly exogenous variation in modification policy induced by lawsuits against Countrywide Financial Corporation, which agreed in October 2008 to offer modifications to seriously delinquent borrowers with subprime mortgages throughout the country. Using a difference-in-difference framework, they find that Countrywide's relative delinquency rate increased more than 10 percent per month immediately after the program's announcement. The borrowers whose estimated default rates increased the most in response to the program were those who appear to have been the least likely to default otherwise, including those

28. Note that we have been able to identify "strategic defaulters" by merging several data sets - many of which were not available for lenders during the crisis period. Moreover, it is not clear that using up-to-date payment information across products to identify such "behavior" is legal from a lender's perspective. 
with substantial liquidity available through credit cards and relatively low combined loan-to-value ratios. Their results suggest that strategic behavior should be an important consideration in designing mortgage modification programs (see also Agarwal, Amromin, et al. 2012).

Overall, the evidence in this section suggests that identifying "eligible" borrowers is a significant challenge for lenders interested in renegotiating with borrowers. There are some borrowers who-given the substantial negative equity in their homes - strategically defaulted on their mortgage payments. In addition, the design of a renegotiation program itself could induce other borrowers to strategically default. The magnitudes of both of these factors seem large enough to have potentially deterred lenders from renegotiating at a higher rate than has been observed. ${ }^{29}$

\section{Political Influence}

Furthermore, we discuss if there is evidence that banks' servicing decisions were also influenced by political pressure. In particular, it is plausible that banks may postpone foreclosures on their own delinquent loans in response to political pressure. Agarwal, Dinc, et al. (2011) provide evidence that is consistent with this conjecture. They show that the start of foreclosure on a delinquent loan is delayed if the loan is located in a congressional district whose representative is a member of the Financial Services Committee in the US House of Representatives.

We show below that these political effects may not have been only limited to bank-held loans by conducting a different variant of tests used in Agarwal, Dinc, et al. (2011). In table 4.4 we conduct our analysis on securitized loans to assess if the time it takes to foreclose on a loan varies depending on whether the servicer is likely to be affected more by political and regulatory pressure. We use the time it takes to foreclose a loan (in months) as the dependent variable and measure it as the time it takes from the incidence of a loan becoming sixty days delinquent until the completion of foreclosure process. The analysis uses data on nonagency securitized mortgages that were foreclosed in the 2004-2010 period (from the BlackBox database) and uses standard controls as well as origination year fixed effects, as well as fixed effects for the year when the foreclosure process began. Importantly, we use servicer information at the loan level to classify them as "independent" if the entity does not have substantial holdings of their own loans and are not directly involved in loan origination process (e.g., Ocwen or Litton). The excluded category consists of the loans handled by big bank servicers (e.g., Citi or Bank of America).

Column (1) of table 4.4 shows that, all else equal, independent servicers

29. The problem of cost-effective design of mortgage modification programs is complicated further by the observation that some of the "strategic defaulters" may be the best candidates for mortgage modification due to their financial ability to service debt. In other words, a group of borrowers with potentially promising modification targets can also display a larger scope for strategic behavior in response to a mortgage modification program. 
Table 4.4

Number of months from last sixty dpd to end of foreclosure

Dependent variable

(1)

(2)

(3)

Average number of months to

foreclosure

6.94

19.66

14.16

\begin{tabular}{lccc}
\cline { 2 - 4 } & All & $2004-2007$ & $2008-2010$ \\
\hline Independent servicer & $-0.766^{* * *}$ & $-0.569^{* * *}$ & $-0.857^{* * *}$ \\
& $(52.44)$ & $(23.83)$ & $(49.83)$
\end{tabular}

Other controls

Origination year fixed effects

Yes

Yes

(49.83)

Foreclosure began year fixed effects

Yes

Yes

Yes

Yes

Yes

Yes

$N$ of loans

$1,598,700$

808,351

Yes

$R^{2}$

0.192

0.103

790,349

0.120

Notes: The dependent variable is the number of months from a loan going $60 \mathrm{dpd}$ for the last time to the loan leaving the sample as a finished foreclosure. The main explanatory variable is whether the servicer of a loan is an independent servicer $(=1)$ or a big bank $(=0)$. In these regressions we include nonlinear controls of FICO, LTV, interest rates, and loan amounts. We also include a dummy for whether the loan was ARM or FRM. Finally, we also use origination year fixed effects as well as fixed effects for the year the foreclosure process began. The data comes from BlackBox database.

***Significant at the 1 percent level.

**Significant at the 5 percent level.

*Significant at the 10 percent level.

foreclose loans faster than big banks by about twenty-three days ( 0.76 of month), a relative reduction of 4.4 percent in foreclosure time. Columns (2) and (3) split the sample based on whether loans entered delinquency in the 2004-2007 period or in the 2008-2010 period, respectively. These results suggest that the gap in foreclosure time between big banks and independent servicers grew over time. We interpret these results as suggesting that big banks - possibly due to stronger political or regulatory pressures - were more lenient in processing foreclosures. Overall, these correlations suggest that political pressure may have played a role in delaying foreclosures, especially during the later end of the crisis.

\section{Role of Servicer-Specific Factors}

Finally, the renegotiation process may have been stymied (or perceived to be stymied) by several other factors. For instance, limited organizational capability or capacity constraints faced by some lenders and servicers during the crisis may have prevented these institutions from developing and implementing cost-effective mortgage modification programs. A recent paper by Agarwal, Amromin, et al. (2012) suggests that the sluggish pace of the loss mitigation process of mortgages following the crisis can be attributed (in part) to the inaction of servicers, likely due to their limited organizational 
capabilities. Moreover, the general downturn in the economy-leading to significant job loss - also contributed to the deepening of the foreclosure crisis.

Since foreclosures tend to result in significant deadweight losses for borrowers and lenders and impose negative externalities for neighborhoods, many federal, state, and local initiatives have been undertaken to combat the foreclosure crisis. We now discuss the most significant initiative undertaken by the federal government to address the factors that were perceived to be hindering renegotiations.

\section{Government Intervention to Stem the Foreclosure Crisis}

There were several reasons why the federal government intervened in the foreclosure crisis. First, as discussed before, foreclosures may exert significant negative externalities that make it socially optimal for government intervention to accelerate the rate of mortgage modifications relative to what lenders and servicers would do privately. Second, as we also discussed, servicers' financial incentives, legal constraints and uncertainty in servicers' contracts, and coordination problems among dispersed investors may have inhibited renegotiation of securitized loans. These coordination problems could be fixed if the government served as a coordinating entity. Third, some lenders and servicers may have become liquidity constrained during the crisis. Consequently, these institutions may not have had sufficient resources required to develop and implement mortgage modification programs. Providing them with subsidies for modification efforts could alleviate their financial constraints, allowing them to modify more loans. Finally, a government-initiated loan modification program could provide a framework to standardize modification efforts, resulting in possible economies of scale and a reduction in borrowers' idiosyncratic incentives to strategically default.

These arguments were central to the Obama administration implementing the Home Affordable Modification Program (HAMP) program, with the hope of bolstering the rate of modifications of residential loans. The HAMP program outline was presented on March 4, 2009. Its two main features consist of, first, a cost-sharing arrangement with mortgage holders and investors designed to help reduce monthly payments on first-lien mortgages, and second, sizable financial incentives to servicers for modifying mortgages under the program. ${ }^{30}$ The Treasury has also committed to use HAMP funds

30. The HAMP committed to onetime incentive payments to servicers of $\$ 1,000$ for each completed renegotiation under the program. Servicers were also eligible for up to $\$ 1,000$ in annual, ongoing pay-for-success incentive payments that would accrue if mortgage payments were made on time for three years after the renegotiation. These incentive payments are sizable relative to the regular annual fees for servicing, which amount to about 20 to 50 basis points of the outstanding loan balance ( $\$ 400$ to $\$ 1,000$ per year for a $\$ 200,000$ outstanding loan balance mortgage). 


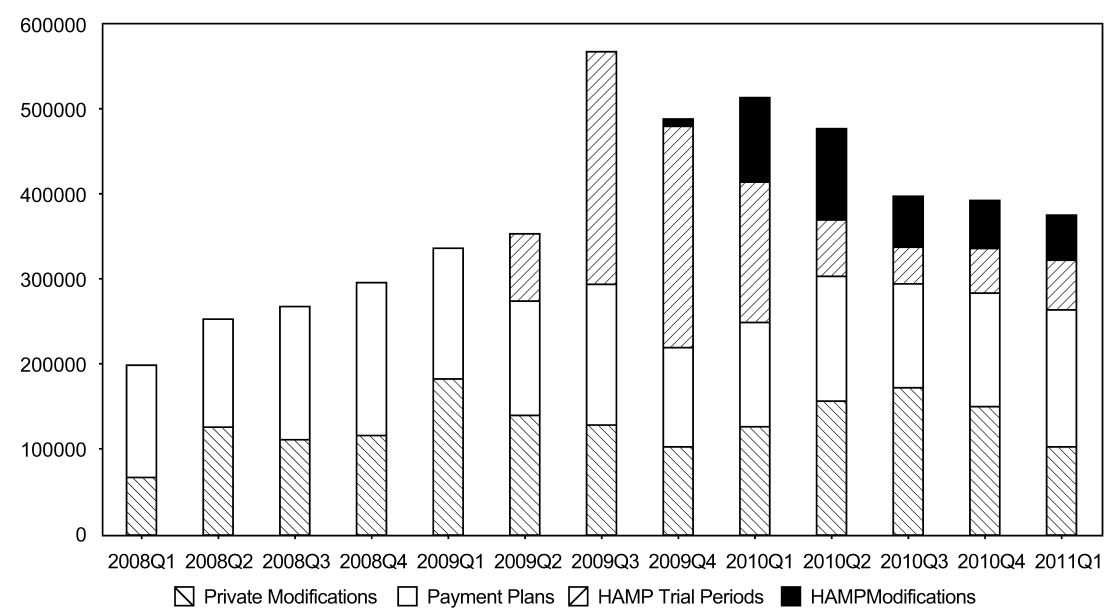

Fig. 4.19 Residential mortgage renegotiations in the United States (2008:Q1 to 2011:Q1)

Source: OCC and OTS Mortgage Metrics Reports, Q1:2009 to Q1:2011.

Notes: This figure presents the number and composition of mortgage renegotiations for residential mortgages over the period 2008:Q1 to 2011:Q1.

to provide both onetime and ongoing "pay-for-success" incentives to borrowers for making payments on modified loans.

When the program was introduced, new borrowers were to be accepted under the program until December 31, 2012. Program payments were to be made for up to five years after the date of entry into a Home Affordable Modification. According to the Government Accounting Office (2010), the budget allocated to HAMP overall was $\$ 50$ billion of Troubled Asset Relief Program (TARP) funds, directed to encourage the modification of mortgages that financial institutions own and hold in their portfolios and mortgages held in private label securitization trusts. In addition, Fannie Mae and Freddie Mac provided an additional \$25 billion to encourage servicers and borrowers to modify loans owned or guaranteed by the GSEs. The expectation of policymakers - given the number of severely indebted households - was that about three to four million home owners would receive assistance with their mortgages during forty-five months of the program. ${ }^{31}$

Figure 4.19 shows residential mortgage renegotiations performed in the OCC data covering more than 60 percent of the mortgage market. We note that just prior to the announcement of the HAMP program, almost 200,000 loans were modified in the first quarter of 2009. In addition, more than

31. This estimate was based on the number of home owners who were likely to be at risk of default (over 10 million homes), to have unaffordable loans (more than 8 million homes), to apply for a loan modification (5.5 million homes), and to pass the net present value (NPV) test (about 4 million homes). See Government Accountability Office (2009). 
100,000 loans were renegotiated using repayment plans. We do observe some modest increase in the number of modified loans after the HAMP passage. However, most of it comes in the form of HAMP trial modifications, which may be subsequently converted into a permanent modification only if the modification is successful during the trial period (i.e., borrowers make payments per the changed contract that was offered on a trial basis, which typically takes about six months). This figure suggests that a majority of trial modifications were not converted into permanent modifications.

A detailed empirical analysis of the effects of HAMP using OCC data is provided by Agarwal, Amromin, et al. (2012). Using a difference-in-difference strategy that exploits variation in program eligibility criteria across comparable borrowers, they estimate that the program resulted in only modest increase in modifications. Overall, they find that the impact of the program will be substantially limited since they estimate that renegotiations induced by HAMP will reach just one-third of its targeted 3 to 4 million indebted households. This shortfall is in large part due to low renegotiation intensity of a few large servicers that responded at half the rate than others. They show that the muted response of these servicers cannot be accounted for by differences in contract, borrower, or regional characteristics of mortgages across servicers. Instead, their low renegotiation activity - which is also observed before the program-reflects servicer-specific factors that appear to be related to their preexisting organizational capabilities. Overall, their findings reveal that the ability of government to quickly induce changes in behavior of large intermediaries through financial incentives is quite limited, underscoring significant barriers to the effectiveness of such polices.

\section{Current Status of the Foreclosure Crisis}

More than 5 million US home owners lost their homes to foreclosure between 2007 and 2010..$^{32}$ More worrisome, an additional 11 million homeowners - nearly one out of every four with a mortgage - are at risk of foreclosure because their homes are worth less than what they owe to mortgage lenders. ${ }^{33}$ As of fall 2011, foreclosure rates are still high by historical standards, with many more expected. The lack of success of either private or government programs suggests that many of the barriers to efficient foreclosure resolution are even more formidable than previously anticipated. The economic downturn has been both more severe and more persistent than many expected, and house prices have not yet bottomed out in many metropolitan areas. Furthermore, underwater home owners and those with limited income have been unable to meet LTV and DTI guidelines set out by federal modification and refinance programs.

The broader lesson from the foreclosure crisis and the glut of vacant hous-

32. See Chen (2010).

33. See CoreLogic (2012). 
ing is that during the boom, residential investment likely reached such levels that resources were ex post inefficiently allocated toward home construction. In many markets, house price growth may have distorted the overall efficiency of productive activity in the economy. It may take some time for the economy to reallocate resources to other productive sectors from housing; among other challenges, it may also require significant retraining of the labor force. This reallocation process is also hampered due to the uncertainty surrounding the future of the GSEs. The current set of lenders are only originating loans eligible for sale to GSEs - the only game in town - while other private participants are reluctant to reenter the mortgage market in which they may have to potentially compete with even larger and stronger GSEs than what they had faced in the early 2000s.

\subsection{Conclusion}

In our discussion of the evolution of the mortgage finance, we have described several factors related to innovation and securitization that led us into the current crisis and factors that allowed the crisis to prolong. We feel that many of these factors have direct implications on issues relevant to policymakers as they embark on redesigning mortgage markets going forward. We now list broad themes that have emerged and the lessons we can draw on each of these based on our analysis.

\subsubsection{Implication 1: Skin in the Game Matters, but Not All Securitizations Are Created Equal}

The first implication that emerges clearly from our analysis is that skin in the game matters for improving the performance of the mortgage pool. Securitization - the act of creating distance between originators of risk and those that bear the risk - requires several actors, each with potentially different interests, in the supply chain of credit. Several pieces of evidence presented here suggest that these conflicting interests can lower the quality of the mortgage pool. We have also emphasized the importance of mechanisms that potentially counteract the weakened incentives of various agents in the supply chain when they respond to greater "ease of securitization."

Going forward, the future design of private securitization will likely implement this lesson by better aligning the interests of lenders, underwriters, and servicers with those of investors. To achieve this goal, it may be beneficial to enforce some mandatory retention of a fraction of lower tranche by originators/underwriters to better align their interests with those of investors. Such retention is consistent with predictions of contracting literature and a component of the Dodd-Frank financial reform act. For example, in a recent theoretical work Hartman-Glaser, Piskorski, and Tchistyi (2012) derive the optimal mortgage-backed security contract in a dynamic setting, in which a mortgage underwriter with limited liability can engage in costly hidden effort 
to screen borrowers and can sell loans to investors. They show that (a) the timing of payments to the underwriter is the key incentive mechanism, (b) the maturity of the optimal contract can be shorter than the maturity of the underlying mortgages, (c) and that bundling mortgages is efficient, as it allows investors to learn about underwriter effort more quickly due to an information enhancement effect. Interestingly, they demonstrate that requiring the underwriter to retain the "first loss piece" can closely approximate the optimal contract. We note, however, that the practical design of such mechanisms is challenging: the appropriate retention will usually vary as a function of collateral, and there is also a legitimate question of how such retention clauses will be enforced in practice.

To shed more light on the importance of risk retention mechanisms, we briefly compare the provision of incentives in the nonagency residential mortgage-backed security market with other asset-backed security markets and argue that all "securitization" is not created the same - that is, there are differences in the nature of financial intermediation across products, and these differences could lead to dramatic differences in their performance.

We begin by describing the differences between credit card and auto loan securitizations and the securitization of nonagency residential mortgages in terms of originators' incentives to screen. In contrast to nonagency mortgages, auto and credit card securitizers ask issuers explicitly to retain first loss pieces on their asset-backed securities transactions. For example, an issuer like Ford Motor makes loans to car buyers through its Ford Motor Credit finance unit, and retains junior loan pieces before underwriters securitize senior loans to be sold as securities. Similarly, in the case of credit card securitization, card issuers only securitize receivables; they do not securitize the accounts themselves. Consequently, the issuer controls the account and retains the "excess spread" - the revenue in surplus of what is needed to pay the asset-backed securities. This provides the issuer with additional "skin in the game."

Similarly, securitization by the GSEs differs from subprime loan securitization on several important dimensions. First, since the buyers of loans are concentrated, it is easier to coordinate and implement standard lending and servicing guidelines across lenders. In addition, because the lenderinvestor relationship is repeated more frequently than in the subprime market, it is also easier to reward or punish lenders and servicers by tracking the performance of collateral originated by different entities. In other words, reputation-based implicit contracts are easier to sustain in this market. Interestingly, the credit card and auto loan securities market, as well as the market for GSE-backed securities, did not experience a collapse similar to that of the private label securitization market. ${ }^{34}$ This may suggest that stron-

34. A similar point is made by Benmelech, Dlugosz, and Ivashina (2012) in the context of securitizations in the corporate loan collateralized loan obligations (CLOs). They show that 
ger mechanisms for aligning incentives between various parties involved could have played an important role in sustaining their functioning during the crisis. $^{35}$

\subsubsection{Implication 2: Focus on What Products Should Be or Should Not Be Securitized}

Our work highlights that issues of moral hazard are important only if the collateral being originated has potentially significant unobservable information associated with it. If hard information variables sufficiently capture the credit quality of the collateral, problems of moral hazard may not be a big issue. In fact, this has been found to be true even within the nonagency part of the securitized markets. As has been shown in Keys et al. (2009, 2010a, 2010b) and Keys, Seru, and Vig (2012), the issue of screening on unobservables is important only if the hard information variables are not likely to be sufficient statistics for a borrower's credit quality. For example, a high FICO borrower is unlikely to have a great deal of unobservable information that, if the lender had carefully collected the information, would fundamentally alter the borrower's predicted default rate. Credit card securitized pools tend to have higher FICO than subprime mortgage securitized pools, suggesting that screening on unobservables might be less of a concern in credit card markets in general. Similarly, loans sold to GSEs have hard information that is likely to be closer to a sufficient statistic of borrowers' credit quality. As a result, screening on unobservables may not be as severe to begin with as it is in the subprime market.

This insight has parallels in the work on financial intermediation. A large body of work shows that banks differ in technologies based on their size, which leads to differing comparative advantage on the products they originate. Small banks lend primarily to "soft information" intensive borrowers because the distance between the loan officers who originate the loan and the decision makers (loan officers) is shorter. Larger banks lend instead to borrowers with hard information, since there is potential information loss

mechanisms in place (including originator reputation) play a significant role in curbing adverse selection.

35. Another securitization structure-conduits-worked well during the crisis (Acharya, Schnabl, and Suarez 2011). We argue that this is the case because the issuers had enough "skin in the game." The conduit structure allows firms such as auto and credit card companies, which have loans on their balance sheets but are unable to access the unsecured commercial paper (CP) market at favorable rates to finance their assets in the asset-backed commercial paper (ABCP) market. Notably, the average age of an ABCP program's assets is significantly longer than the maturity of its commercial paper, and maturing paper is continually being repaid with the proceeds of new issues ("rolling"). This mismatch of assets and liabilities introduces liquidity risk into the ABCP product: should a conduit become unable to roll existing liabilities, the administrator must find another way to pay investors. To address these risks, most ABCP programs include explicit "liquidity backstops," or standing facilities that can be drawn upon in the event that the conduit is unable to rollover maturing paper, and which cover the conduit's obligations. The facility, either a loan or an asset purchase agreement, is generally provided by a commercial bank. Thus, the bank providing the liquidity facility has incentives to monitor the lenders originating the collateral that backs the pool due to threat of a run (as in Diamond and Rajan 2001). 
between loan officers who originate the loan and decision makers (higherlevel bank officials). This research suggests that large banks would face adverse selection on unobservables if soft information intensive borrowers were able to get loans from large banks.

Our findings are consistent with this evidence. Securitization creates a distance between the originator and the final bearer of risk, and therefore can be thought of as movement from a small bank to a large bank. Consequently, we find that loans where soft information is important are precisely the ones where informational problems occur - with investors holding loans that are worse on unobservables.

\subsubsection{Implication 3: A Redesign of the Securitization Chain Should Not Ignore Other Agency Conflicts}

The current crisis has also emphasized that the potential agency conflicts between underwriters and investors do not arise only during the mortgage origination process and its subsequent sale. Of great importance are also potential conflicts arising during the process of servicing these assets (Piskorski, Seru, and Vig 2010). Any new securitization design needs to anticipate these conflicts and allow investors better control of how their investments are managed. An important insight of our work is that an ideal securitization market would be more robust with better provisions for the possibility of mortgage workouts in a crisis. This could be achieved by building more state-contingencies into servicing contracts. For example, mortgages at risk of foreclosure could be transferred to special servicers according to similar rules as used in the commercial MBS market. Alternatively, some adjustments of mortgage terms due to changes in regional economic conditions may be directly built up into the mortgage contracts (see Shiller 2008; Piskorski and Tchistyi 2011). Moreover, the evidence provided by Mayer et al. (2011) suggests that more work should be done to design efficient mortgage modification programs that take into account borrowers' strategic responses to such policies.

\subsubsection{Implication 4: Regulation That Proclaims That "One Size Fits All" Ignores the Evidence}

Our results do not necessarily support the view that the Dodd-Frank mandate of 5 percent risk retention is the optimal amount of risk retention in the mortgage market. We find a great deal of heterogeneity across market segments in the ability of lenders to behave strategically; in some segments of the market, 5 percent may not be enough to strengthen incentives, while in others, retaining a 5 percent portion of the loan pool may be prohibitively costly to fund private label securitizations. Although our results provide broad support for skin in the game, we would need a complex structural model of pool performance and information frictions to estimate the optimal level of risk retention for a given type of underlying mortgage assets. 


\subsubsection{Important Caveats}

While our line of research uncovers some potential costs of securitization, it is not questioning the potential benefits of this financial innovation. Securitization leads to better risk-sharing and can result in potentially financing value-creating investments that would otherwise be difficult to finance. There is large evidence in the literature on the benefits accruing to financially constrained banks, which, due to securitization, were able to fund new projects and sustain the adverse effects of monetary shocks on their balance sheets.

Were many of the effects we found ex ante priced by investors? While this is an important question, there are two obstacles in answering this question. First, data on the prices of various tranches in the MBS market is difficult to obtain. Most data vendors who provide the data make available prices that are "model" generated, rather than ones actually paid by investors. Second, it is hard to know what "correct" pricing means without a comprehensive structural model that maps various factors into a pricing function. Several papers show that the riskiness of the pool (as measured by ex post quality) and some ex ante pricing variable (like subordination rate) are positively correlated. Indeed, that is the same result we find (e.g., table 4.2, column [1]). However, without having a clear model to infer what the price should have been - given the riskiness of the pool — it is difficult to make assertions about optimal or correct pricing. As far as we are aware, no such model exists, but developing one is a fruitful area of future research.

It is important to note that while we refrain from making any welfare claims, there could have been distortions introduced in the real economy due to the effects we document, even if investors rationally priced the effect of securitization on screening. In particular, it is possible that regulators and rating agencies may have perceived some securitized assets to be less risky than they actually were if they relied on preboom data to evaluate the quality of securitized loans. As a result, banks' capital requirements may not have adjusted sufficiently for the risk of some securitized assets. Understanding the behavior of regulators and rating agencies in the period before and during the crisis remains another promising area of research.

Overall, our work seeks to emphasize that there are potential costs to the securitization process in practice, and that these costs must be recognized when designing the financial infrastructure for mortgage lending in the future.

\section{Data Appendix}

We use several sources of mortgage data to conduct our analysis. The first source of data is from LoanPerformance, who maintain a loan-level database that provides a detailed perspective on the nonagency securities market. The data includes, as of December 2006, more than 7,000 active home equity 
and nonprime loan pools that include more than 7 million active loans, with over $\$ 1.6$ trillion in outstanding balances. LoanPerformance estimates that, as of 2006, the data covers over 90 percent of the universe of securitized nonprime loans. The data set includes all standard loan application variables such as the loan amount, loan-to-value (LTV) ratio, FICO credit score, and interest rate. The major limitation of the data set is that it does not have information on unsold loans.

Our next source of data comes from the Lender Processing Services (LPS) database (formerly "McDash"), which combines characteristics of the loan and borrower at the time of origination with monthly payment information. The LPS data contain loan-level information on unsold loans, loans securitized by government-sponsored enterprise (GSEs), and loans securitized through private investors. In addition, similar to the LoanPerformance data set, LPS also includes all standard loan application variables such as the loan amount, LTV ratio, FICO credit score, and interest rate. The downside of the data is that its coverage of subprime loans is significantly limited, especially for loans originated prior to 2005.

Each of these data sets contains information about the property being financed by the borrower and the purpose of the loan. Specifically, we have information on the type of mortgage loan (fixed rate, adjustable rate, balloon, or hybrid) and the zip code where the dwelling is located. Typically, loans are classified as either for purchase or refinance, though in this chapter we focus exclusively on loans for home purchases. We restrict our sample to cover owner-occupied single-family residences, townhouses, or condominiums (single-unit loans account for more than 90 percent of the loans in our sample). We also drop nonconventional properties, such as those that are Federal Housing Administration (FHA)- or Veterans Administration(VA)insured or pledged properties, and also exclude buy down mortgages. Only those loans with valid FICO scores are used in our sample.

In general, we assess borrower creditworthiness along two dimensions. First, we use borrower credit scores, known as "FICO" scores, as a measure of credit risk. These scores provide a ranking of potential borrowers by the probability of having some negative credit event in the next two years, with nearly all scores between 500 and 800 (see Avery et al. 1996). Second, we use the level of documentation of income and assets collected by the lender as a proxy of borrower quality. Documentation in the market (and reported in the database) is categorized as full, limited, or no documentation. Borrowers with full documentation verify both income and assets. Borrowers with limited documentation usually provide no information about their income but do provide some about their assets. "No-documentation" borrowers provide no information about income or assets, which is a very rare degree of screening lenience on the part of lenders. In our analysis, we combine limited and no-documentation borrowers and call them low-documentation borrowers.

Next, in some of our analysis we use information from a database of lenders' required disclosure to the federal government under the Home Mort- 
gage Disclosure Act (HMDA). The HMDA data set, hosted at the Federal Reserve Bank of New York, covers the period from 1990 to 2008, though newer data have been collected, as lenders are still required to report this information. In several of our analyses we will use information from other sources (e.g., prospectuses of MBS). We discuss these sources closer to where we conduct the analysis.

Finally, in some of our analysis we use data that links two databases: (a) loan-level mortgage data on nonagency securitized mortgages collected by BlackBox Logic, and (b) borrower-level credit report information collected by Equifax. BlackBox data, which has similar coverage as the LP database, account for about 90 percent of all privately securitized mortgages. The BlackBox data, which are obtained from mortgage servicers and securitization trustees, include static information taken at the time of origination, such as mortgage date and amount, FICO credit score, servicer name, interest rate, term, and interest rate type. The BlackBox data also include dynamic data on monthly payments, mortgage balances, and delinquency status. Equifax is a credit reporting agency that provides monthly data on borrowers' current credit scores, payments and balances on mortgage and installment debt, and balances and credit utilization for revolving debt (such as credit cards and HELOCs). These databases were merged by 1010Data, a provider of data warehousing and processing, using a proprietary match algorithm.

We note that there is no consensus on definition of a "subprime" mortgage. The term subprime usually refers to a loan (mortgage, auto, etc.) that is viewed as riskier than a regular (prime) loan in the eyes of a lender. It is riskier because the expected probability of default for these loans is higher. There are several definitions of subprime available in the industry. A subprime loan can be (a) originated to a borrower with a low credit score and/or history of delinquency or bankruptcy, and/or poor employment history; (b) originated by lenders specializing in high-cost loans who sell few loans to the GSEs; (c) part of a subprime security (called B\&C or Alt-A securities in Wall Street parlance); and/or (d) a mortgage (e.g., a 2/28 or 3/27 "hybrid" mortgage) generally not available in the market where the GSEs operate.

\section{References}

Acharya, Viral, Philipp Schnabl, and Gustavo Suarez. 2012. "Securitization without Risk Transfer." Journal of Financial Economics. Available online as of October 12, 2012: http://dx.doi.org/10.1016/j.jfineco.2012.09.004.

Adelino, Manuel, Kristopher Gerardi, and Paul S. Willen. 2010. "Why Don't Lenders Renegotiate More Home Mortgages? Redefaults, Self-Cures and Securitization." Federal Reserve Bank of Atlanta Working Paper.

Agarwal, Sumit, Gene Amromin, Itzhak Ben-David, Souphala Chomsisengphet, and Douglas D. Evanoff. 2011a. "Market-Based Loss Mitigation Practices for 
Troubled Mortgages Following the Financial Crisis." Federal Reserve Bank of Chicago Working Paper no. 2011-03.

2011b. "The Role of Securitization in Mortgage Renegotiation." Journal of

Financial Economics. http://dx.doi.org/10.1016/j.jfineco.2011.07.005.

Agarwal, Sumit, Gene Amromin, Itzhak Ben-David, Souphala Chomsisengphet, Tomasz Piskorski, and Amit Seru. 2012. "Policy Intervention in Debt Renegotiation: Evidence from Home Affordable Modification Program." Working Paper. Available at SSRN: http://ssrn.com/abstract=2138314.

Agarwal, Sumit, Gene Amromin, Itzhak Ben-David, Souphala Chomsisengphet, and Yan Zhang. 2011. "Second Liens and the Holdup Problem in First Mortgage Renegotiation." Working Paper. Available at SSRN: http://ssrn.com/abstract=2022501.

Agarwal, Sumit, Gene Amromin, Itzhak Ben-David, and Serdar Dinc. 2011. "The Politics of Foreclosure." National University of Singapore, Working Paper.

Agarwal, Sumit, and Calvin T. Ho. 2007. "Comparing the Prime and Subprime Mortgage Markets." Chicago Fed Letter, Number 241.

Agarwal, Sumit, David Lucca, Amit Seru, and Francesco Trebbi. 2012. "Inconsistent Regulators: Evidence from Banking." NBER Working Paper no. 17736. Cambridge, MA: National Bureau of Economic Research.

Ambrose, Brent, Anthony Sanders, and Abdullah Yavas. 2011. "Special Servicers and Adverse Selection in Informed Intermediation: Theory and Evidence."Pennsylvania State University, Working Paper.

Ashcraft, Adam, and Til Schuermann. 2008. "Understanding the Securitization of Subprime Mortgage Credit.” Federal Reserve Bank of New York Staff Report no. 318.

Avery, Robert, Raphael Bostic, Paul Calem, and Glenn Canner. 1996. "Credit Risk, Credit Scoring and the Performance of Home Mortgages." Federal Reserve Bulletin 82:621-48.

Barlevy, Gadi, and Jonas Fisher. 2010. "Mortgage Choices and Housing Speculation." Federal Reserve Bank of Chicago Working Paper.

Belsky, Eric S., and Nela Richardson. 2010. "Understanding the Boom and Bust in Nonprime Mortgage Lending." Harvard Joint Center for Housing Studies Working Paper.

Ben-David, Itzhak. 2011. "Financial Constraints and Inflated Home Prices during the Real Estate Boom.” American Economic Journal: Applied Economics 3 (3): 55-78.

Benmelech, Efraim, Jennifer Dlugosz, and Victoria Ivashina. 2012. "Securitization without Adverse Selection: The Case of CLOs." Journal of Financial Economics 106 (1): 91-113.

Bhutta, Neil, Jane Dokko, and Hui Shan. 2010. "The Depth of Negative Equity and Mortgage Default Decisions." FEDS Working Paper 2010-35.

Bolton, Patrick, and Howard Rosenthal. 2002. "Political Intervention in Debt Contracts." Journal of Political Economy 110 (5): 1103-34.

Bond, Philip, David K. Musto, and Bilge Yilmaz. 2005. "Predatory Lending in a Rational World." Federal Reserve Bank of Philadelphia Working Paper no. 06-2.

Bubb, Ryan, and Alex Kaufman. 2009. "Securitization and Moral Hazard: Evidence from Credit Score Cutoff Rules." Federal Reserve Bank of Boston Working Paper no. 0905 .

- 2011. "Further Investigations into the Origin of Credit Score Cutoff Rules." NYU School of Law Working Paper.

Bucks, Brian K., and Karen M. Pence. 2008. "Do Borrowers Know Their Mortgage Terms?" Journal of Urban Economics 64 (2): 218-33.

Buiter, Willem H. 2008. "Lessons from the North Atlantic Financial Crisis." Paper presented at "The Role of Money Markets" Conference, Columbia Business School and the Federal Reserve Bank of New York. May 29-30. 
Campbell, John Y., and Joao F. Cocco. 2011. "A Model of Mortgage Default." NBER Working Paper no. 17516. Cambridge, MA: National Bureau of Economic Research.

Campbell, John Y., Stefano Giglio, and Parag Pathak. 2011. "Forced Sales and House Prices." American Economic Review 101(5): 2108-31.

Chen, Celia. 2010. "Foreclosures Cloud the Housing Outlook." Moody's Analytics Regional Financial Review. November.

Chomsisengphet, Souphala, and Anthony Pennington-Cross. 2006. "The Evolution of the Subprime Mortgage Market.” St. Louis Federal Reserve Review, JanuaryFebruary 88 (1): 31-56.

Citigroup Global Markets. 2009. "A Brief (and Complete) History of Loan Modifications." Working Paper.

Cocco, Joao F. 2011. "Understanding the Trade-offs of Alternative Mortgage Products.” Working Paper. Available at SSRN: http://ssrn.com/abstract=1572603.

Corbae, Dean, and Erwan Quintin. 2011. "Mortgage Innovation and the Foreclosure Boom." University of Texas-Austin, Working Paper.

CoreLogic. 2012. "CoreLogic Reports Negative Equity Increase in Q4 2011." http:// corelogic.com/about-us/news/asset_upload_file909_14436.pdf.

Demiroglu, Cem, and Christopher M. James. 2012. "How Important Is Having Skin in the Game? Originator-Sponsor Affiliation and Losses on Mortgage-Backed Securities." Review of Financial Studies 25 (11): 3217-58.

Demyanyk, Yuliya, and Otto Van Hemert. 2009. "Understanding the Subprime Mortgage Crisis." Review of Financial Studies. doi:10.1093/rfs/hhp033.

Deng, Yongheng, John Quigley, and Robert Van Order. 2000. "Mortgage Terminations, Heterogeneity, and the Exercise of Mortgage Options." Econometrica 68:275-307.

Diamond, Douglas W., and Raghuram Rajan. 2001. "Liquidity Risk, Liquidity Creation, and Financial Fragility: A Theory of Banking." Journal of Political Economy 109 (2): 287-327.

Dunn, Kenneth B., and Chester S. Spatt. 1985. "An Analysis of Mortgage Contracting: Prepayment Penalties and the Due-on-Sale Clause." Journal of Finance 40:293-308.

Favilukis, Jack, Sydney Ludvigson, and Stijn Van Nieuwerburgh. 2010. "The Macroeconomic Effects of Housing Wealth, Housing Finance, and Limited Risk-Sharing in General Equilibrium.” NBER Working Paper no. 15988. Cambridge, MA: National Bureau of Economic Research.

Gan, Yingjin, and Christopher Mayer. 2006. "Agency Conflicts, Asset Substitution, and Securitization.” NBER Working Paper no. 12359. Cambridge, MA: National Bureau of Economic Research.

Gelpern, Anna, and Adam J. Levitin. 2009. "Rewriting Frankenstein Contracts: The Workout Prohibition in Residential Mortgage-Backed Securities." Southern California Law Review 82:1077-152.

Goldstein, Debbie, and Stacy Strohauer Son. 2003. "Why Prepayment Penalties Are Abusive in Subprime Home Loans." Center for Responsible Lending Policy Paper no. 4.

Government Accountability Office. 2006. Alternative Mortgage Products: Impact on Defaults Remains Unclear, but Disclosure of Risks to Borrowers Could Be Improved. GAO-06-1021, September.

- 2009. Treasury Actions Needed to Make the Home Affordable Modification Program More Transparent and Accountable. GAO-09-837, July 23.

. 2010. Home Affordable Modification Program Continues to Face Implementation Challenges. GAO-10-556T, March 25.

Guiso, Luigi, Paola Sapienza, and Luigi Zingales. 2009. "Moral and Social Con- 
straints to Strategic Default on Mortgages.” NBER Working Paper no. 15145. Cambridge, MA: National Bureau of Economic Research.

Hartman-Glaser, Barney, Tomasz Piskorski, and Alexei Tchistyi. 2012. "Optimal Securitization with Moral Hazard.” Journal of Financial Economics 104 (1): 186202.

Holmstrom, Bengt, and Paul Milgrom. 1991. "Multitask Principal-Agent Analyses: Incentive Contracts, Asset Ownership, and Job Design." Journal of Law, Economics, \& Organization 7:24-52.

Jiang, Wei, Ashlyn Aiko Nelson, and Edward Vytlacil. 2009. "Liar's Loan? Effects of Origination Channel and Information Falsification on Mortgage Delinquency." Indiana University Bloomington, School of Public and Environmental Affairs Research Paper no. 2009-06-02.

. 2010. "Securitization and Loan Performance: A Contrast of Ex Ante and Ex Post Relations in the Mortgage Market." Working Paper. Available at SSRN: http://ssrn.com/abstract=1571300.

Kau, James B., Donald C. Keenan, and Taewon Kim. 1994. "Default Probabilities for Mortgages.” Journal of Urban Economics 35:278-96.

Keys, Benjamin J., Tanmoy Mukherjee, Amit Seru, and Vikrant Vig. 2009. "Financial Regulation and Securitization: Evidence from Subprime Loans." Journal of Monetary Economics 56 (5): 700-20.

—.2010a. "Did Securitization Lead to Lax Screening? Evidence from Subprime Loans." Quarterly Journal of Economics 125:307-62.

2010b. "620 FICO, Take II: Securitization and Screening in the Subprime Mortgage Market.” University of Chicago, Working Paper.

Keys, Benjamin J., Amit Seru, and Vikrant Vig. 2012. "Lender Screening and Role of Securitization: Evidence from Prime and Subprime Mortgage Markets." Review of Financial Studies 25 (7): 2071-108.

Khan, James A., 2008. "Housing Prices, Productivity Growth and Learning." Working Paper. Federal Reserve Bank of New York.

Landier, Augustin, David Sraer, and David Thesmar. 2010. "Going for Broke: New Century Financial Corporation, 2004-2006.” IDEI Working Papers 649. Toulouse: Institut d'Économie Industrielle (IDEI).

Loutskina, Elena, and Philip E. Strahan. 2011. "Informed and Uninformed Investment in Housing: The Downside of Diversification." Review of Financial Studies 24 (5): 1447-80.

Makarov, Igor, and Guillaume Plantin. 2011. "Equilibrium Subprime Lending." Journal of Finance, forthcoming.

Mayer, Christopher, Edward Morrison, and Tomasz Piskorski. 2009. "A New Proposal for Loan Modifications.” Yale Journal on Regulation 26:417-29.

Mayer, Christopher, Edward Morrison, Tomasz Piskorski, and Arpit Gupta. 2011. "Mortgage Modification and Strategic Behavior: Evidence from a Legal Settlement with Countrywide." NBER Working Paper no. 17065. Cambridge, MA: National Bureau of Economic Research.

Mayer, Christopher, Karen Pence, and Shane Sherlund. 2009. "The Rise in Mortgage Defaults." Journal of Economic Perspectives 23:27-50.

Mayer, Christopher, Tomasz Piskorski, and Alexei Tchistyi. 2010. "The Inefficiency of Refinancing: Why Prepayment Penalties Are Good for Risky Borrowers." Journal of Financial Economics. Available online October 13, 2012. http://dx.doi. org/10.1016/jfineco.2012.10.003.

Melzer, Brian. 2012. "Debt Overhang: Reduced Investment by Homeowners with Negative Equity." Kellogg School of Management, Working Paper.

. 2011. "The Real Costs of Credit Access: Evidence from the Payday Lending Market.” Quarterly Journal of Economics 126 (1): 517-55. 
Mian, Atif, and Amir Sufi. 2009. "The Consequences of Mortgage Credit Expansion: Evidence from the US Mortgage Default Crisis." Quarterly Journal of Economics 124:1449-96.

2011. "House Prices, Home Equity-Based Borrowing, and the US Household Leverage Crisis." American Economic Review 101 (5): 2132-56.

Mian, Atif, Amir Sufi, and Francesco Trebbi. 2011. "Foreclosures, House Prices, and the Real Economy." NBER Working Paper no. 16685. Cambridge, MA: National Bureau of Economic Research.

Nadauld, Taylor D., and Shane M. Sherlund. 2009. "The Role of the Securitization Process in the Expansion of Subprime Credit." Finance and Economics Discussion Series (FEDS) Working Paper no. 2009-28. Board of Governors of the Federal Reserve System.

Pence, Karen M. 2006. "Foreclosing on Opportunity: State Laws and Mortgage Credit."' Review of Economics and Statistics 88:177-82.

Piskorski, Tomasz, Amit Seru, and Vikrant Vig. 2010. "Securitization and Distressed Loan Renegotiation: Evidence from the Subprime Mortgage Crisis." Journal of Financial Economics 97:369-97.

Piskorski, Tomasz, and Alexei Tchistyi. 2010. "Optimal Mortgage Design.” Review of Financial Studies 23:3098-140.

- 2011. "Stochastic House Appreciation and Optimal Mortgage Lending." Review of Financial Studies 24:1407-46.

Posner, Eric A., and Luigi Zingales. 2009. "A Loan Modification Approach to the Housing Crisis." American Law and Economics Review 2009:1-33.

Purnanandam, Amiyatosh. 2011. "Originate-to-Distribute Model and the Subprime Mortgage Crisis.” Review of Financial Studies 24 (6): 1881-915.

Rajan, Uday, Amit Seru, and Vikrant Vig. 2010. "The Failure of Models that Predict Failure: Distance, Incentives and Defaults.” Chicago GSB Research Paper no. 08-19.

Sherlund, Shane M. 2008. "The Past, Present, and Future of Subprime Mortgages." FEDS Working Paper no. 2008-63. Board of Governors of the Federal Reserve System.

Shiller, Robert J. 2008. The Subprime Solution: How Today's Global Financial Crisis Happened, and What to Do About It. Princeton, NJ: Princeton University Press.

Stein, Jeremy C. 2002. "Information Production and Capital Allocation: Decentralized vs. Hierarchical Firms." Journal of Finance 57:1891-921.

Stevens, David H. 2011. "Legislative Proposals to End Taxpayer Funding for Ineffective Foreclosure Mitigation Programs.” Written Testimony of David H. Stevens, Assistant Secretary of Housing, Federal Housing Administration. Hearing before the House Financial Services Committee's Subcommittee on Insurance, Housing, and Community Opportunity. March 2.

Van den Heuvel, Skander J. 2008. "The Welfare Cost of Bank Capital Requirements." Journal of Monetary Economics 55 (2): 298-320.

White, Alan M. 2009a. "Deleveraging the American Homeowner: The Failure of 2008 Voluntary Mortgage Contract Modifications." Connecticut Law Review 41:1107-31.

_ 2009b. "Rewriting Contracts, Wholesale: Data on Voluntary Mortgage Modifications from 2007 and 2008 Remittance Reports." Fordham Urban Law Journal 36:509-35.

Zhang, Yan. 2011. "Does Loan Renegotiation Differ by Securitization Status? An Empirical Study.” Working Paper. Available at SSRN: http://ssrn.com/abstract $=1773103$. 